\title{
Uma abordagem em grafo-e/ou para o problema de corte bidimensional não-guilhotinado
}

Aluna: Silvely Nogueira de Almeida Salomão Orientação: Prof. Dr. Marcos Nereu Arenales

Dissertação apresentada ao Instituto de Ciências Matemáticas de São Carlos, da Universidade de São Paulo, como parte dos requisitos para obtenção do título de Mestre em Ciência da Computação e Matemática Computacional.

São Carlos ICMSC/USP julho de 1993 
Como é que alguém pode descobrir o sentido das coisas que acontecem? Isto é profundo demais para nós e muito difícil de entender. Mas resolvi estudar e conhecer as coisas.

(...) Tudo o que aprendi se resume nisto:

Deus nos fez simples e direitos, mas nós complicamos tudo.

SALOMÃO - (Eclesiastes 7: 24, 25 e 29) 


\section{Resumo}

Este trabalho propõe uma resolução para o problema de corte não guilhotinado através do grafo-E/OU. Considera uma placa retangular que pode ser cortada em dois tipos de padróes de corte, não-guilhotinado de ordens 0 e 1 . O objetivo é encontrar uma maneira ótima de cortá-la em peças menores. 


\begin{abstract}
This work suggests a resolution for the non-guillotine cutting problem by AND/OR-graph. There is a rectangular plate that can be cut only two kinds of cutting patterns, the order 0 and 1 non-guillotine. The objective is to find the optimal manner of cutting it in smaller pieces.
\end{abstract}




\section{Agradecimentos}

À meus pais, Leão e Sylvia, por terem me incentivado e acreditado em mim em todos os momentos.

À Lecil, Luciana, Alexandre e Bruno por terem sempre sido uma família maravilhosa.

Às tias Marile e Esmeralda por todas orações feitas a meu favor, com a certeza de que todas foram atendidas de forma ótima.

Ao Marcos pela oportunidade de ser orientada por ele e pela paciência e dedicação com que fez isto.

À Simone, Lucival, Tereza Cristina, Suzana, Lucy, Fátima, Douglas, Luciano, Guillermo, Moniche, Raquel e Ana Cristina pela amizade e principalmente por terem sempre um ouvido disponivel.

Aos professores, em especial à Roseli Francelin pela amizade e incentivo, pelos conhecimentos que dividiram comigo.

Aos funcionários, em especial ao Elien, Luciano, Sônia, Beth e Laura, pela boa vontade que sempre desempenharam sua funções.

À CAPES pelo apoio financeiro. 


\section{Conteúdo}

0 Introdução

I Conceitos básicos

1 Noções preliminares

1.1 Classificação de peças . . . . . . . . . . . . . . 5

1.2 Classificação dos cortes $\ldots \ldots \ldots \ldots \ldots \ldots \ldots$

2 O problema de corte $\quad 11$

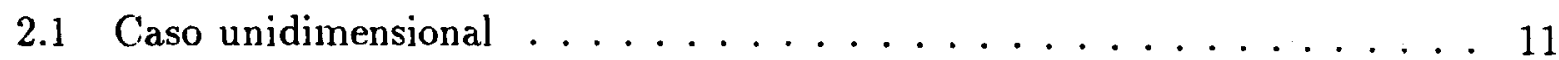

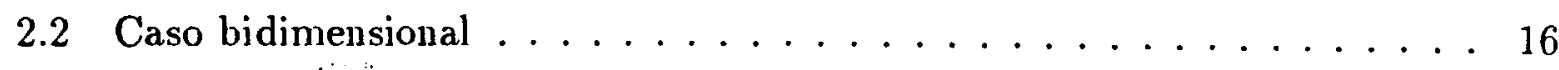

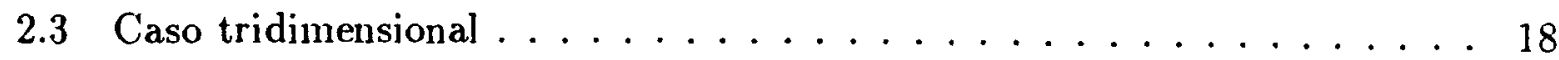

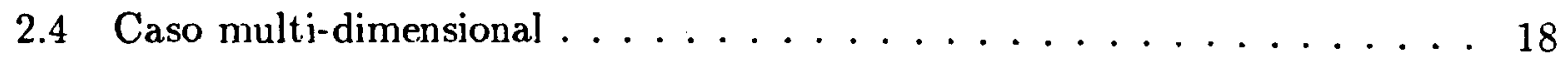

II Revisão bibliográfica $\quad 20$

3 Representação em grafo-E/OU 


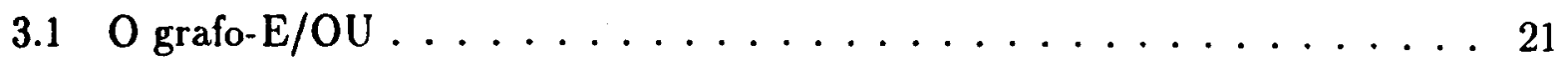

4 Programa linear 0-1 e cortes não guilhotinados 29

4.1 Formulação natemática . . . . . . . . . . . . . 29

5 Fluxos em rede no caso não-guilhotinado $\quad 35$

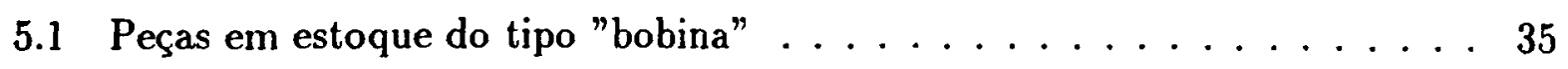

III Proposta de resolução para o caso bidimensional nãoguilhotinado

6 Cortes não-guilhotinados no grafo-E/OU

6.1 Cortes não-guilhotinados de ordem $0 \ldots \ldots$. . . . . . . . 43

6.2 Cortes não-guilhotinados de ordem $1 \ldots \ldots \ldots 4$

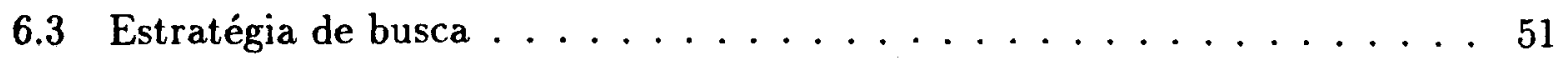

IV Considerações finais $\quad 54$

7 Conclusão $\quad \mathbf{5 5}$

$\begin{array}{lll}\text { Apêndice A } & \text { Relaxação lagrangeana e método do subgradiente } & 58\end{array}$

$\begin{array}{ll}\text { Bibliografia } & 61\end{array}$ 


\section{Lista de Figuras}

0.1 Corte (A) guilhotinado e (B) não-guilhotinado em uma peça retangular

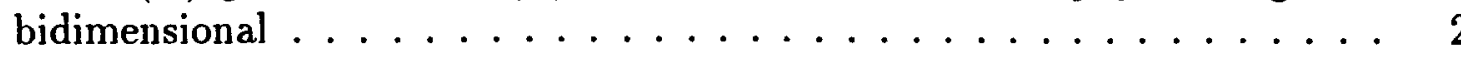

1.1 Exemplos de peças: (A) unidimensional; (B) bidimensional; e (C) tridi-

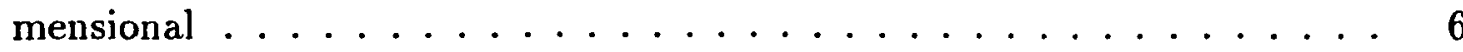

1.2 Corte de uma peça de tecido para confeç̧ão de calças . . . . . . . . . . 7

1.3 Peças $(\mathrm{A})$ regulares e $(\mathrm{B})$ irregulares $\ldots \ldots \ldots \ldots \ldots$

1.4 Cortes guilhotinados $(\mathrm{A})$ regulares e $(\mathrm{B})$ irregulares. . . . . . . . . . . 8

1.5 Padrões de corte (A) guilhotinado e (B) não-guilhotinado. . . . . . . . . 9

1.6 Uma peça cortada em dois estágios. . . . . . . . . . . . . 10

2.1 Peças em estoque (objetos) e de encomenda (itens) no caso unidimensional. 12

2.2 Diferentes padrões aplicados ao objeto $1 \ldots \ldots \ldots$

2.3 Padrões de corte não-guilhotinado de ordem $1 \ldots \ldots$. . . . . . . 17

2.4 Problemas de corte tridimensional . . . . . . . . . . . . . . . 18

2.5 Corte multidimensional . . . . . . . . . . . . . . 19

3.1 Arco-E para cortes guilhotinados. . . . . . . . . . . . . . 22

3.2 Outros arcos-E para o retângulo da figura $3.1 \ldots \ldots \ldots$ 
3.3 Arco-E para padrôes não-guilhotinados de ordem $1 \ldots 25$

3.4 Padrào de corte que envolve apenas cortes nâo-guilhotinados de ordens 0 e 125

3.5 Grafo-E/OU para o padrão de corte da figura $3.4 \ldots \ldots$

3.6 Padrâo duplicado . . . . . . . . . . . . . . . . 26

3.7 Padrôes de cortes nâo normalizado (A) e normalizado (B) . . . . . . . . 27

4.1 Alocação de uma peça através do corte não-guilhotinado . . . . . . . . . 30

4.2 Sobrepusiçáo de peças no ponto $(2,1) \ldots \ldots \ldots \ldots$. . . . . . . . 31

5.1 Peças em estoque do tipo bobina. . . . . . . . . . . . 36

5.2 Capacidades $c_{i, j}$ relativos a $R_{1}$ e $R_{3} \ldots \ldots \ldots \ldots$

5.3 Rede-R para o conjunto $R=\left\{R_{1}, R_{2}, R_{3}, R_{4}\right\} \ldots \ldots \ldots$

5.4 Padrào P para a bobina de comprimento 8 e $R . \ldots$. . . . . . . . 39

5.5 Representaçâo do fluxo do padrão P na Rede- $R$. . . . . . . . . . . 40

6.1 Exemplo do grafo-E/OU para o caso não-guilhotinado de ordem 0 . . . . 44

6.2 Melhor solıçâo para a busca no grafo-E/OU da figura 6.1. . . . . . . 45

6.3 Simetria en cortes não-guilhotinados de ordem $1 \ldots \ldots 6$

6.4 Padrâu nìu-guilhotinado de ordens 0 (A) e 1 (B) equivalentes . . . . 48

6.5 Processu de ıormalização para um padrão não-guilhotinado de ordem 1 . . 48

6.6 Arcos- $\mathrm{E}$ dos padrôes não-guilhotinados de ordem 1 aplicados ao grafo-

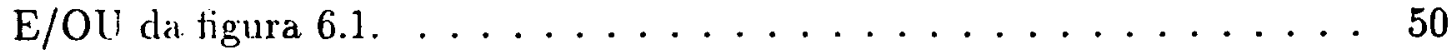

6.7 Melhor soluçào para o exemplo tomado. . . . . . . . . . . 51

7.1 Padrão obtido para o exemplo $1 . \ldots \ldots \ldots \ldots$ 
7.2 Padrão obtido para o exemplo $2 \ldots \ldots \ldots \ldots$ 


\section{Lista de abreviações}

- s.à: = sujeito à

- $\lceil\mathrm{x}\rceil=$ menor inteiro maior que $\mathrm{x}$

- $\lfloor x\rfloor=$ maior inteiro menor que $x$

- $|X|=$ cardinalidade do conjunto $X$ 


\section{Capítulo 0}

\section{Introdução}

É freqüente em indústrias a produção de peças menores a partir de peças maiores. As sobras obtidas através dos cortes, podem ser significativas, dependendo da quantia de peças cortadas.

Uma maneira de otimizar o corte seria minimizar as sobras. 0 problema que tratamos neste estudo considera que cada peça menor é retangular e tem um valor associado a ela. O objetivo do problema é encontrar o melhor modo a produzir as peças menores de forma que a somatória de seus respectivos valores seja o máximo possível.

Se cortássemos uma peça retangular de uma extremidade à outra (oposta), de maneira que o resultado fossem dois novos retângulos estaríamos usando um corte com o efeito de guilhotina. Este corte é conhecido como guilhotinado, veja a figura 0.1.(A).

Os estudos referentes ao problema de corte para produçâo de retângulos podem ser subdivididos em guilhotinados (Gilmore \& Gomory[1965], Christofides \& Whitlock[1977], Oliveira \& Ferreira[1990], Morabito et al.[1991]) e não-guilhotinados (Beasley[1985a, 1985b], Biró \& Boros[1984], Bischoff, E. \& Dowsland, W.B.[1982]), ou seja, não restritos ao efeito de uma guilhotina, veja a figura 0.1.(B).

Análogo ao problema de corte, temos o problema de empacotamento e carregamento, onde temos que agrupar peças em uma embalagem de maneira ótima. Bischoff, $\mathrm{E}$. \& Dowsland, W.B.[1982] apresentaram um algoritmo de resolução para o problema de carregamento de paletes e contêineres considerando, em particular, padrões de distribuição de peças equivalentes a padrôes de cortes não-guilhotinados.

Neste estudo apresentamos resumidamente os principais trabalhos de cortes 

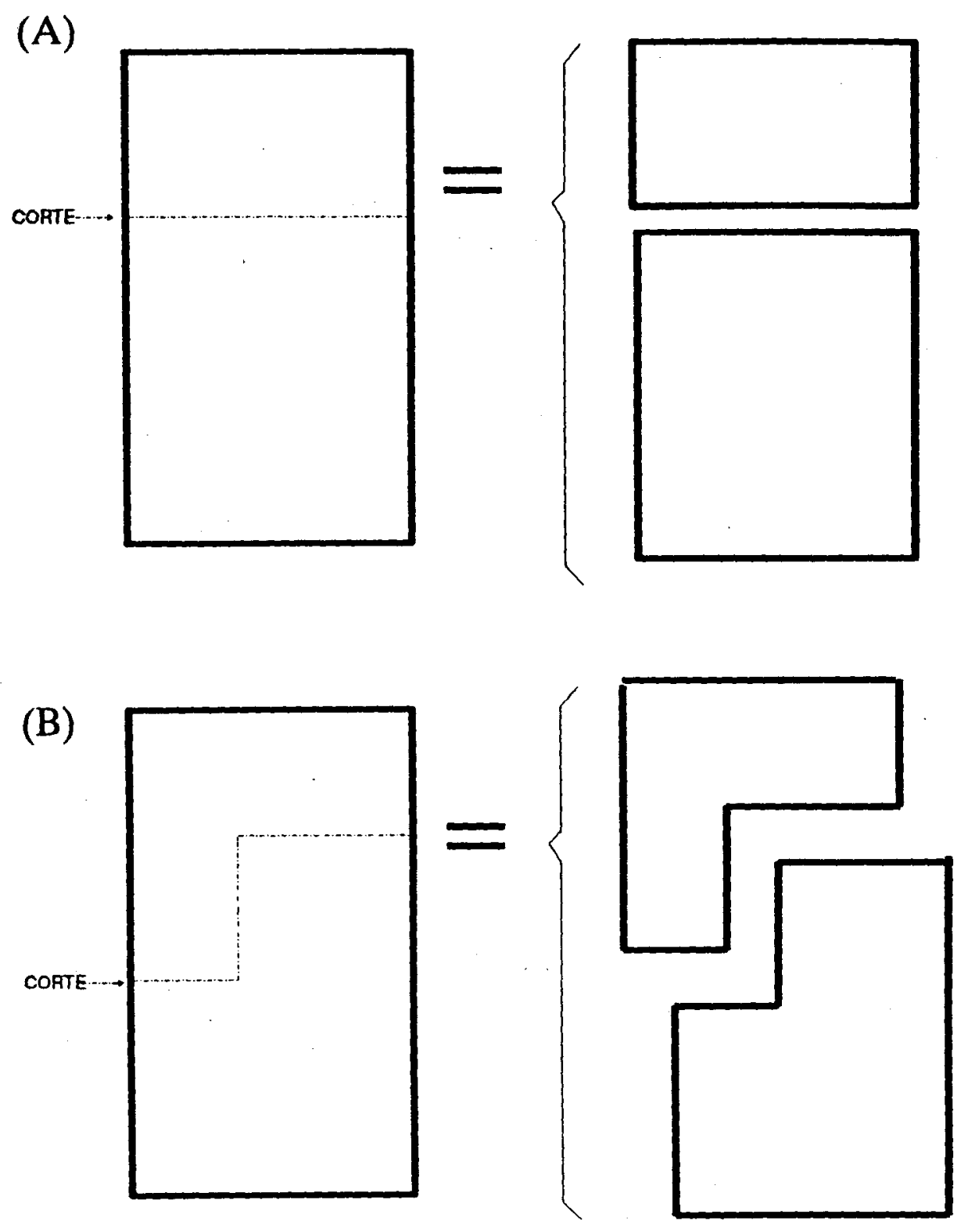

Figura 0.1: Corte (A) guilhotinado e (B) não-guilhotinado em uma peça retangular bidimensional 
não-guilhotinados e propomos uma nova representação em grafo-E/OU que generaliza os trabalhos de Morábito et al.[1992] e Bischoff, E. \& Dowsland, W. B. [1982]. Apresentamos regras de redução do espaço de estados evitando soluçôes simétricas.

Os capítulos são distribuídos em quatro partes, como a seguir.

A Parte I, composta pelos capítulos 1 e 2, fornece os conceitos básicos relativos a problemas de cortes em geral. O capítulo 1 faz uma classificação segundo os tipos de peças e cortes utilizados e capítulo 2, os tipos de problemas considerados na literatura.

$\mathrm{Na}$ Parte II, captítulos 3 à 5, fazemos uma revisão bibliográfica voltada, mais especificamente, à nossa proposta, que é o problema bidimensional não-guilhotinado. No capítulo 3, temos um estudo do grafo-E/OU para o caso guilhotinado. Para o caso nãoguilhotinado no capítulo 4, apresentamos o estudo de Beasley e no capítulo 5 o de Biró \& Boros [1984].

O capitulo seguinte, formando a parte III, propõe a extensão do grafo-E/OU para produção de padrões não-guilhotinados. Na parte IV apresentamos o capítulo 7 com conclusões dos resultados obtidos.

$\mathrm{Na}$ parte final temos o apêndice A e a bibliografia utilizada. 


\section{Parte I}

Conceitos básicos 


\section{Capítulo 1}

\section{Noções preliminares}

O modo como os cortes são aplicados faz variar substancialmente a abordagem de resoluçâo do problema. Neste capítulo são apresentados alguns dos conceitos relativos à classificação dos problemas de cortes.

\subsection{Classificação de peças}

Enfocaremos basicamente as dimensões, material e regularidades das peças e tipos de cortes possíveis. Uma classificação mais geral pode ser encontrada em Morabito[1992].

\section{Dimensões das peças}

O problema geral de cortes consiste em otimizar o corte de uma ou mais peças grandes, chamadas peşas em estoque, na produção de outras menores, chamadas peças de encomenda, as quais têm valores associados. Por exemplo, cortar uma peça retangular de comprimento $L_{0}$ e largura $W_{0}$, que denotaremos por $A_{0}=\left(L_{0}, W_{0}\right)$. em $\mathrm{m}$ peças menores $A_{i}=\left(l_{i}, w_{i}\right)$ com um valor $v_{i}$ associado a elas, $\mathrm{j}=1,2, \ldots, \mathrm{m}$. Observamos que os valores para os comprimentos e larguras são inteiros.

Podemos classificar as peças quanto às dimensôes:

Definição 1 (Dimensões de uma peça.) Uma peça é unidimensional quando ape- 


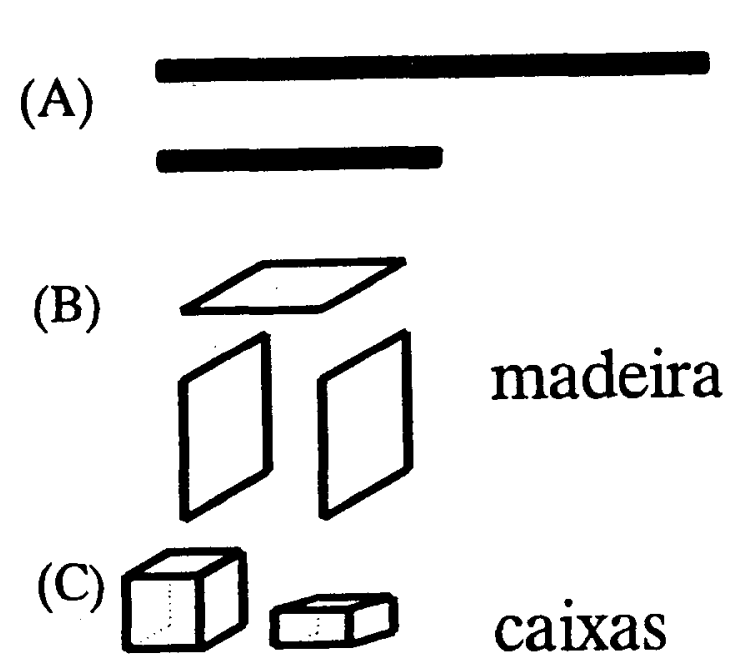

Figura 1.1: Exemplos de peças: (A) unidimensional; (B) bidimensional; e (C) tridimensional

nas uma das dimensōes (por exemplo comprimento) é relevante. Se duas dimensōes são relevantes, a pesca é dita bidimensional. A definição para tridimensional é análoga.

Na figura 1.1 observamos barras de aço (onde apenas o comprimento das barras é considerado), peças de madeiras para manufatura de móveis e caixas para carregamento em contêineres. São exemplos que representam peças uni, bi e tridimensionais, respectivamente.

\section{Material}

Também podemos classificar as peças pelo material que ela é constituida e o propósito pelo qual ela é cortada.

Definição 2 (Peça iso e anisotrópica.) Uma peça é denominada anisotrópica quando a orientaşâo do corte na peşa influencia na qualidade dos itens produzidos. Caso não 


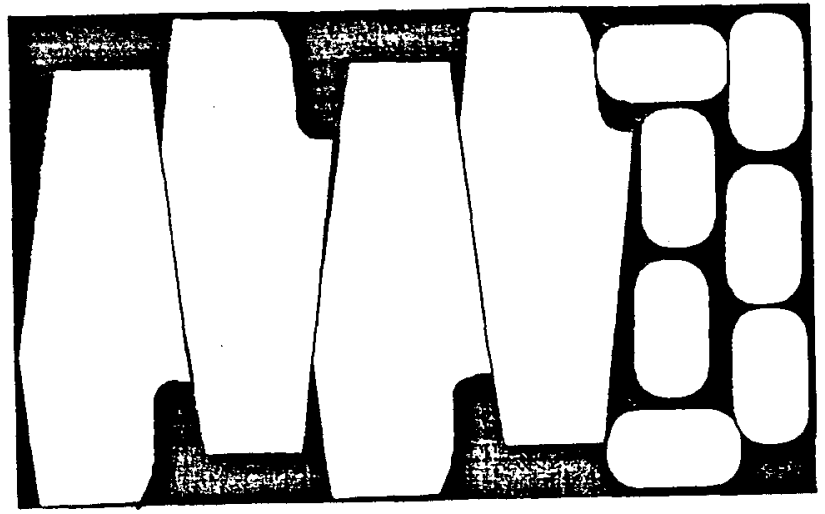

Figura 1.2: Corte de uma peça de tecido para confecção de calças

(A)

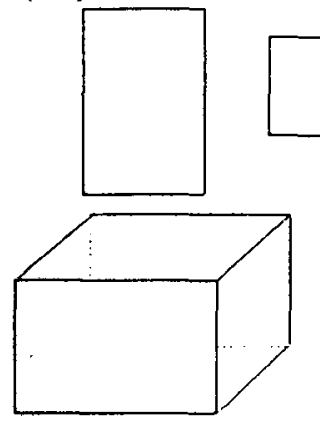

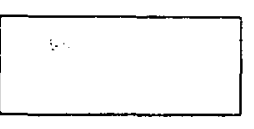

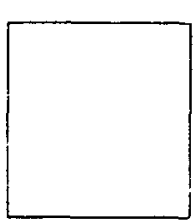

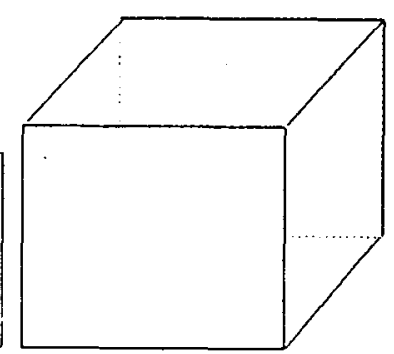

(B)

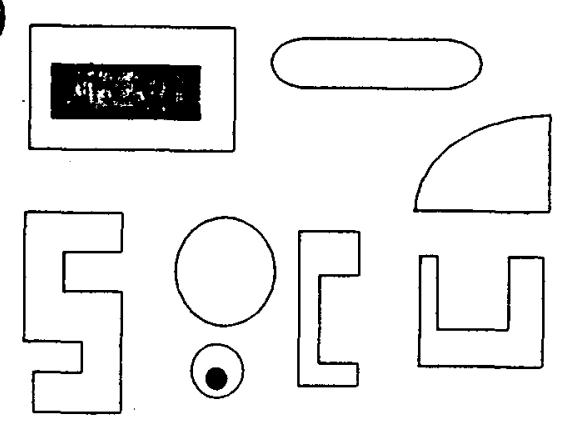

Figura 1.3: Peças (A) regulares e (B) irregulares

haja conseqüências desta natureza a peça é isotrópica.

O exemplo da figura 1.2 mostra o corte de uma peça de tecido para a confecçào de calças. Neste caso a orientação das fibras tem papel fundamental na qualidade do produto final.

\section{Regularidades}

As peças também podem ser classificadas como regulares e irregulares, veja a figura 1.3 . 
(A)

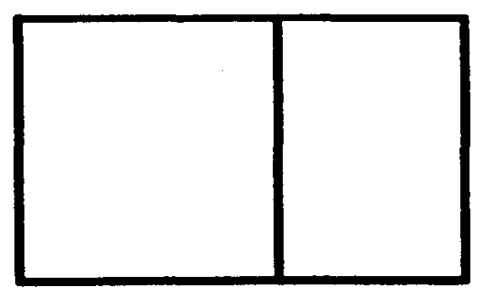

(B)

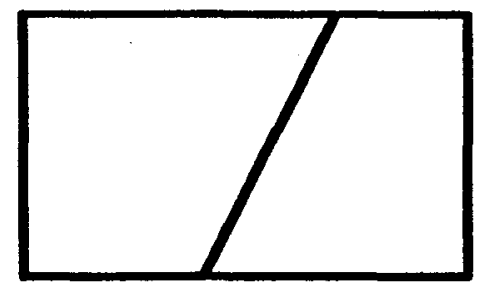

Figura 1.4: Cortes guilhotinados (A) regulares e (B) irregulares.

Definição 3 (Regularidade de uma peça.) As peças são ditas regulares quando são retângulos, no caso bidimensional, ou paralelepipedos no caso tridimensional. Caso contrário são irregulares.

\subsection{Classificação dos cortes}

Para o problema de corte encontramos diferentes tipos de cortes estudados na literatura. Definiremos os mais usados.

Definição 4 (Corte guilhotinado e não-guilhotinado.) Um corte é guilhotinado se é restrito ao efeito de uma guilhotina. Caso contrário é não-guilhotinado.

Um corte guilhotinado é dito regular se produz dois novos retângulos. A figura 1.4 mostra cortes guilhotinados (A) regulares e (B) irregulares. Neste trabalho a referência corte guilhotinado indica regularidade.

Definição 5 (Padrão de corte.) lim padrão de corte é a disposição particular das peças de encomendas sobre uma pȩ̧a em estoque. Tal disposiçâa é obtida por possiveis cortes.

cados.

Um padrão de corte pode ser classificado em função dos tipos de cortes apli-

Definição 6 (Padrão de corte guilhotinado.) Um padrão de corte é dito guilhotinado quando a disposiçâo das peças de encomenda está de tal forma que é possivel obtê-las por cortes guilhotinados. Caso contrário é dito não-guilhotinado. 
(A)

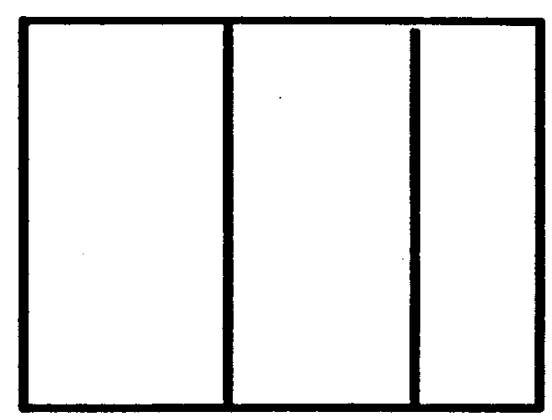

(B)

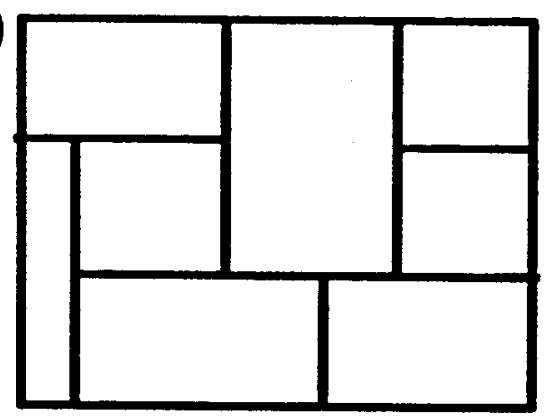

Figura 1.5: Padrões de corte (A) guilhotinado e (B) não-guilhotinado. lhotinado (B).

A figura 1.5 ilustra dois padrões de cortes, um guilhotinado (A) e um nâo-gui-

Numa peça podem ser realizados vários cortes guilhotinados, que são feitos em etapas. Veja figura 1.6: primeiro são realizados dois cortes horizontais: 1 e $2 \mathrm{e}, \mathrm{em}$ seguida, são obtidas três peças que são cortadas com cortes verticais: $3,4,5$ e 6 . Primeiro foram feitos todos os cortes horizontais e depois todos os verticais, cada mudança na direção chamamos estágio.

Definição 7 (Padrão de corte estagiado e multi-estagiado.) Um padrão de corte é estagiado ou $\eta$-estagiado quando o número de estágios é limitado, ou seja, sâo feitos no máximo em $\eta$ estágios. Caso não exista este limitante o padrâo é multi-estagiado.

Um padrão de corte produz um único tipo ou diferentes tipos de peças. Podemos ter padrão homogêneo e padrão näo-homogêneo.

Definição 8 (Padrão de corte homogêneo e não-homogêneo.) Um padrão de corte é dito homogêneo se produz um único tipo de peça. Caso contrário é não-homogêneo.

No capítulo 2 tratamos dos tipos de problemas existentes na literatura. 


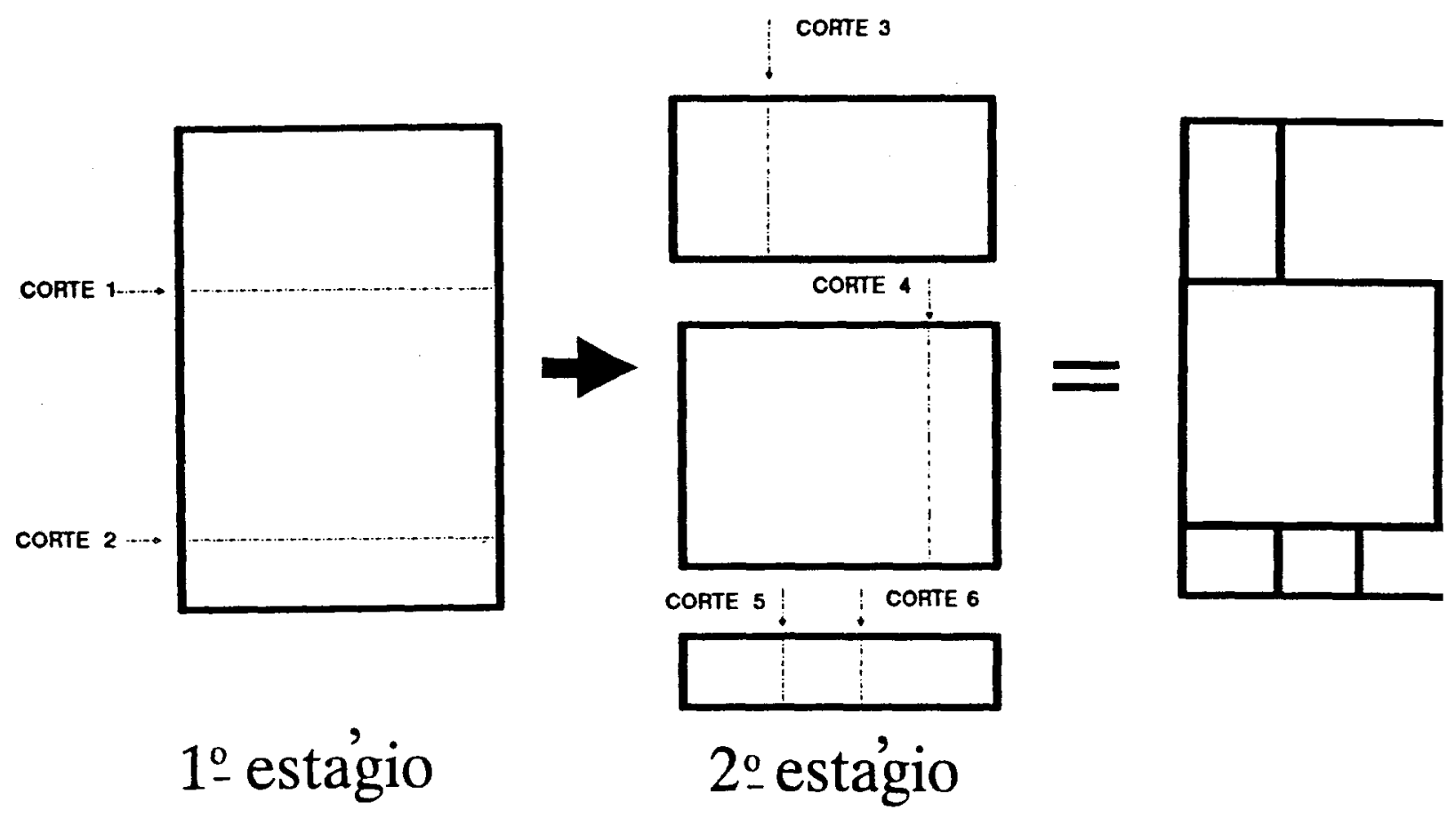

Figura 1.6: Uma peça cortada em dois estágios. 


\section{Capítulo 2}

\section{O problema de corte}

Neste capítulo fazemos uma classificação dos problemas de corte conforme suas dimensões abordando algumas particularidades existentes. As seções 2.1, 2.2 e 2.3 tratam dos casos uni, bi e tridimensional, respectivamente.

\subsection{Caso unidimensional}

O problema de corte unidimensional trata de peças unidimensionais, englobando também peças de outras dimensões, desde que o interesse se volte apenas a uma das dimensôes.

A formulação do problema unidimensional depende de fatores variados. Por exemplo, da quantia de peças de encomenda demandada e a quantia de peças em estoque disponível.

Usaremos o termo objetos para nos referir às peças em estoque e jtens para as peças de encomenda. A figura 2.1 ilustra o caso unidimensional geral. Supondo que temos n tipos de objetos, cada um tem dimensão $\left(L_{j}\right)$, disponibilidade $\left(B_{j}\right)$, ou seja, $B_{j}$ peças disponiveis em estoque e um valor $\left(V_{j}\right)$ referente ao custo unitário $(\mathrm{j}=1,2, \ldots, \mathrm{n})$. Do mesmo modo, temos $m$ tipos de itens, cada um tem dimensão $\left(l_{i}\right)$, a demanda $\left(b_{i}\right)$ a ser satisfeita e um valor $\left(v_{i}\right)$ de utilidade $(i=1,2, \ldots, \mathrm{m})$.

Um padrào de corte $\mathrm{P}$ aplicado a um objeto $\mathrm{j}$ produz uma quantia $a_{j p}^{i}$ de itens do tipo i. Na figura 2.2 temos três diferentes padróes aplicados ao objeto 1. O padrão 1 produz somente 3 itens do tipo 1 , ou seja, $a_{11}^{1}=3$ e $a_{11}^{2}=a_{11}^{3}=\ldots=a_{11}^{m}=0$, que 


\section{OBJETOS}

tipo dimensão
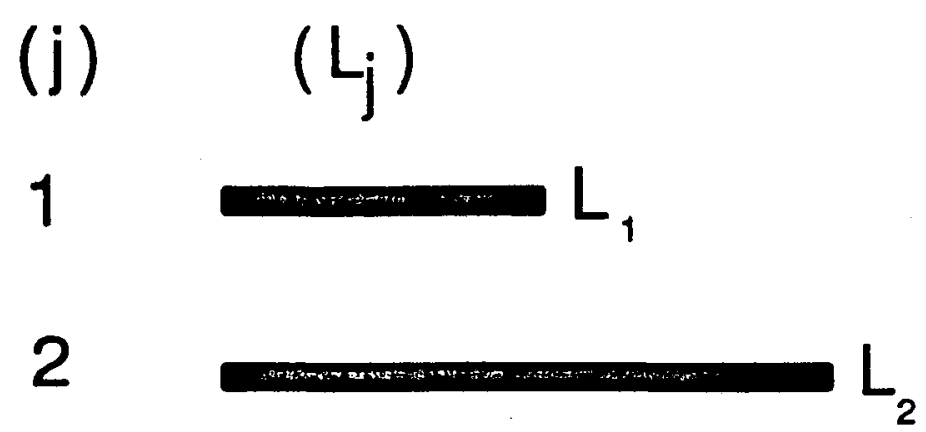

n

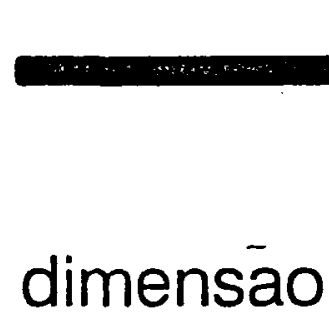

\section{ITENS}

tipo dimensāo

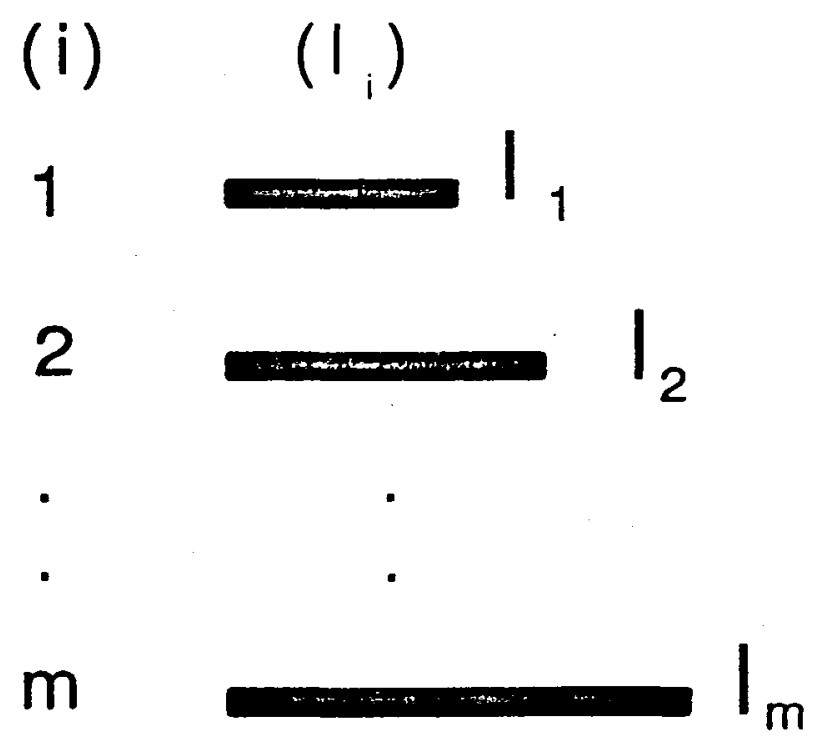

disponibilidade valor

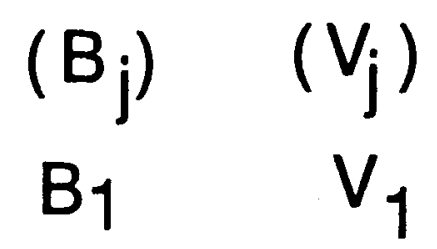

$\mathrm{B}_{2}$

$\mathrm{v}_{2}$

$B_{n}$

$\mathrm{v}_{\mathrm{n}}$ demanda valor
$\left(b_{i}\right)$
$\left(v_{i}\right)$
$b_{1}$
$\mathbf{V}_{1}$

$b_{2}$

$v_{2}$

$b_{m}$

Figura 2.1: Peças em estoque (objetos) e de encomenda (itens) no caso unidimensional. 


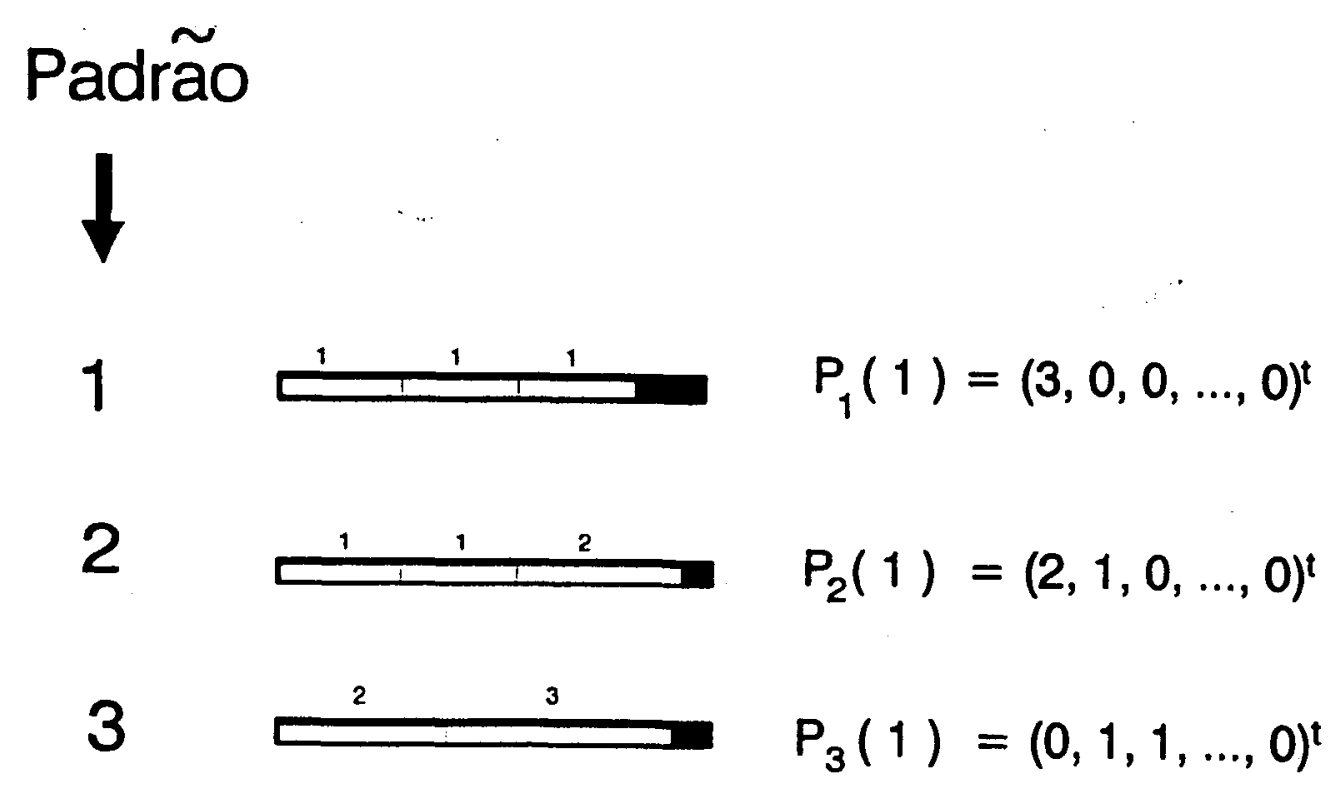

Figura 2.2: Diferentes padrões aplicados ao objeto 1 .

denotaremos pelo vetor $\left(a_{j p}^{1}, a_{j p}^{2}, \ldots, a_{j p}^{m}\right)^{t}=(3,0, \ldots, 0)^{t}$. Analogamente as quantias de itens produzidos pelos padróes 2 e 3 são representados pelos vetores $(2,1,0, \ldots, 0)^{t}$ e $(0$, $1,1,0, \ldots, 0)^{t}$, respectivamente.

Assim, a cada padrão $\mathrm{P}$ podemos definir uma função $P_{p}(\mathrm{j})$ que associa a cada objeto j um vetor $\left(a_{j p}^{1}, \ldots, a_{j p}^{m}\right)^{t}$ do conjunto $N^{m}$ das m-uplas de números naturais:

$$
P_{p}:\left(\text { objeto j) } \rightarrow\left(a_{j p}^{1}, \ldots, a_{j p}^{m}\right)^{t}\right.
$$

Définição 9 (Problema restrito.) Se existe um limitante superior $b_{i}$ para cada $a^{i}=$ $\sum_{p} \sum_{j} a_{j p}^{i}$ (número total de peças do tipo $i$ produzidas), ou seja, $a^{i} \leq b_{i}(i=1,2, \ldots, m)$ o problema de corte é dito restrito.

Em relação à disponibilidade dos objetos, uma classificação consiste em dividir os problemas de corte onde os objetos são suficientes ou não para atender a demanda de itens. Para a insuficiência destacamos o caso onde temos apenas uma peça em estoque; veja a seguir. 


\section{Objeto único a ser cortado} expomos abaixo.

Kantarovich ${ }^{1}$, citado por Schrijver[1986], estudou este caso particular como

Seja L o comprimento do objeto a ser cortado, o modelo matemático é:

$$
\begin{gathered}
\max : \sum_{i=1}^{m} v_{i} a^{i} \\
\text { s.à: } \sum_{i=1}^{m} l_{i} a^{i} \leq L \\
0 \leq a^{i} \leq b_{i} \text { e inteiros }
\end{gathered}
$$

onde $v_{i}$ é real e $a^{i}, l_{i}$, para $i=1,2, \ldots, m, L$ são inteiros positivos. As soluçôes factíveis de 2.2 e 2.3 fornecem padrões de cortes para o problema unidimensional e restrito, isto é, para uma solução particular de 2.2 e $2.3,\left(a^{1}, \ldots, a^{m}\right)^{t}$, existe um padrão de corte $\mathbf{p}$ para o objeto tal que $P_{p}($ objeto $)=\left(a^{1}, \ldots, a^{m}\right)^{t}$.

Nem sempre é possivel estabelecer relações matemáticas sobre $\left(a^{1}, \ldots, a^{m}\right)^{t}$, de modo que, este seja imagem de um padrão de corte para objetos de múltiplas dimensões.

Este é o clássico problema da mochila, cujo nome vem da seguinte situação hipotética: considere um andarilho que está carregando uma mochila com sua bagagem. Para carregar a mochila ele deve escolher entre muitas coisas, cada uma tem um peso e un valor; certamente, ele prefere carregá-la com a quantia máxima dè valor. $O$ peso total que ele levará consigo é limitado por sua capacidade. Assim, seja $l_{j}$ o peso, $v_{j}$ o valor e $a^{j}$ o número de itens do tipo j que o andarilho levará e seja $\mathrm{L}$ a limitação do peso total, assim a formulação do problema é a mesma que a representada no problema acima.

O problema da mochila se caracteriza por ser NP-completo (veja Schrijver[1986], p.249), ou seja, não existe nenhum algoritmo que resolva o problema em tempo polinomial. Embora seja NP-completo, o problema da mochila tem sido solucionado com eficiência na prática, através de uma combinação de métodos de busca em árvore, métodos de programaçâo dinâmica, heurísticas, e podas na árvore de decisão através de limitantes (método branch-and-bound).

\footnotetext{
${ }^{1}$ KA NTAROVICH, L. V. (1939), Mathematical Methods of Organization and Planning Production (em Russo), Publicação House of the Leningrad State University, Leningrad, 1939 [Tradução para o Inglês: Management Science 6 (1959-60) 366-422]
} 
Muitos outros autores estudaram soluçôes para o problema da mochila. Balas \& Zemel $^{2}$, citados por Schrijver[1986,p.372], relataram ter resolvido problemas gerados aleatoriamente com mais de 10.000 variáveis em tempo menor que um segundo. Este problema tem sido objeto de atenção de muitos estudiosos da área nos últimos anos.

\section{Vários objetos (suficientes para atender a demanda)}

Uma formulação para o problema seria:

$$
\begin{gathered}
\min : \sum_{j=1}^{n} V_{j} A_{j} \\
\text { s.à: } \sum_{j=1}^{n} \sum_{p=1}^{A_{j}} P_{p}(j)=\left(b_{1}, b_{2}, \ldots, b_{m}\right)^{t} \\
A_{j} \leq B_{j} \text { onde } j=1,2, \ldots n
\end{gathered}
$$

onde :

- n é o número de tipos de objetos;

- $\mathrm{B}_{j}$ é o número de objetos do tipo $\mathrm{j}$ disponíveis;

- $A_{j}$ é o número de vezes que o objeto j é cortado e

- $b_{i}$ é o número de itens do tipo i que devem ser produzidos.

Neste problema, em particular, o objetivo é minimizar o custo total dos objetos necessários para o corte. No caso unidimensional este objetivo poderia ser, por exemplo, utilizar uma metragem mínima. Neste caso, a função objetivo seria $\min \sum_{j=1}^{n} L_{j} A_{j}$.

Em particular, se definirmos:

$x_{j p}=$ número de vezes que o padrão $\mathbf{p}$ é usado no objeto $\mathrm{j}$, ou seja, $A_{j}=\sum_{p} x_{j p}$. Então o problema dado por $2.4-2.6$ pode ser:

$$
\operatorname{minimize} \sum_{p} \sum_{j=1}^{n} V_{j} x_{j p}
$$

\footnotetext{
${ }^{2}$ BALAS, E. e ZEMEL, E. (1980)," An algorithm for large zero-one knapsack problems ",Operations Research $28(1980) 1130-1154$.
} 


$$
\begin{aligned}
& \text { s.à: } \sum_{j=1}^{n} \sum_{p} P_{p}(j) x_{j p}=\left(b_{1}, b_{2}, \ldots, b_{m}\right)^{t} \\
& \sum_{p} x_{j p} \leq B_{j}, j=1,2, \ldots, n \\
& x_{j p} \geq 0 \text { e inteiro. }
\end{aligned}
$$

Este modelo foi explorado por Gilmore \& Gomory[1961,1963,1965] utilizando uma estratégia de geração de colunas, uma vez que o número de padrôes de corte é muito grande, e cada coluna deste modelo é determinada por $\left[P_{p}(j), 0, \ldots 1, \ldots, 0\right]^{t}$ e $P_{p}(j)=$ $\left[a_{j p}^{1}, \ldots, a_{j p}^{m}\right]^{t}$ é obtido resolvendo-se um problema da mochila.

Existem muitas outras maneiras de formular o problema de corte unidimensional, dependendo das particularidades que cada problema possui. Procuramos introduzir as noçôes básicas para uma classificação que também ocorrerá em problemas de outras dimensões.

\subsection{Caso bidimensional}

O problema de corte bidimensional aplica-se ao corte de vidros, madeiras para manufatura de móveis, chapas de aço, etc.

Assim como o problema unidimensional, existem diferentes formas de abordar o problema bidimensional, variando de acordo com suas características particulares e forma de pesquisa de cada autor. Um exemplo pode ser encontrado em Christofides \& Whitlock[1977], que estudaram o problema bidimensional guilhotinado no caso restrito. A seguir veja o problema tratado por estes.

Seja o retângulo $A_{0}=\left(L_{0}, W_{0}\right)$ o objeto em estoque e $R$ um conjunto de $m$ retângulos menores, $\mathrm{R}=\left\{\left(\mathrm{l}_{1}, \mathrm{w}_{1}\right), \ldots,\left(\mathrm{l}_{m}, \mathrm{w}_{m}\right)\right\}$, onde $\mathrm{L}_{0}, \mathrm{~W}_{0} . \mathrm{l}_{i}, \mathrm{w}_{i}$ são inteiros positivos. Cada peça de $\mathrm{R}$ tem um valor $\mathrm{v}_{i}$ associada a ela e um número máximo $\mathrm{b}_{i}$ de vezes que pode ser cortado de $A_{0}$. O objetivo do problema é:

$$
\max z=\sum_{i=1}^{m} a^{i} v_{i}
$$

sujeito à: $P\left(A_{0}\right)=\left(a^{1}, \ldots, a^{m}\right)^{t}$.

com $a^{i}$ inteiro positivo $\mathrm{e}$

$a^{i} \leq b_{i}$. 

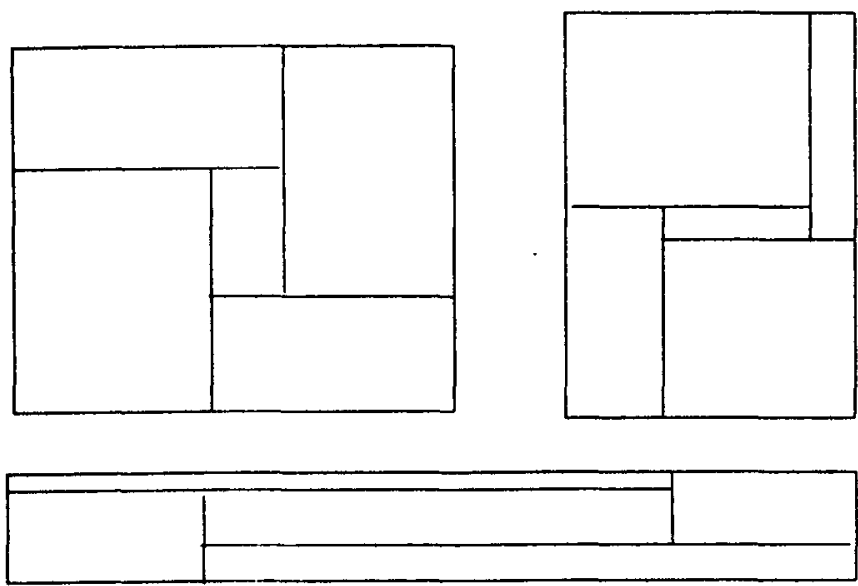

Figura 2.3: Padrões de corte não-guilhotinado de ordem 1

$\mathrm{Na}$ literatura encontramos outros estudos para o caso guilhotinado, como Gilmore \& Gomory[1965], Farley[1990], etc. No capítulo 4 estudaremos a resolução proposta por Morabito[1989]. Para o caso não-guilhotinado temos Bischoff, E. \& Dowsland, W. B. [1982], Beasley[1985a, 1985b], e um caso especial apresentado por Biró \& Boros[1982]. Nos capítulos 4 e 5 faremos uma breve revisão dos trabalhos de Biró \& Boros[1984] e Beasley[1985a], respectivamente.

Os métodos usados para resolução de problemas não-guilhotinados têm se mostrados os mais diversos. Bischoff, E. \& Dowsland, W. B. [1982] desenvolveram um procedimento para resolver o problema de carregamento de paletes e utilizaram-se de uma divisão no palete, equivalente a um padrão de corte não-guilhotinado, definido abaixo.

Definição 10 (Padrão de corte não-guilhotinado de ordem 1) Definimos padrão de corte não-guilhotinado de ordem 1, um padrão composto de quatro cortes: dois horizontais e dois verticais. Cada um perpendicular a um dos lados, formando cinco retângulos: um interior $\epsilon$ quatro nas fronteiras do retângulo maior, veja figura 2.3 .

Biró \& Boros[1984] propuseram um modelo de fluxo em grafos para construir um padrão de corte não-guilhotinado em uma peça regular de comprimento fixo $L$ e altura W variável com o objetivo de utilizar o mínimo de altura possivel e satisfazer a demanda.

Beasley[1985a] propôs um modelo de programação linear 0-1 para o problema bidimensional não-guilhotinado. Estudou o problema restrito e para a resolução utilizou a busca em árvore binária e também de formas de redução para a árvore em questão. Maiores detalhes deixamos aos capítulos posteriores. 

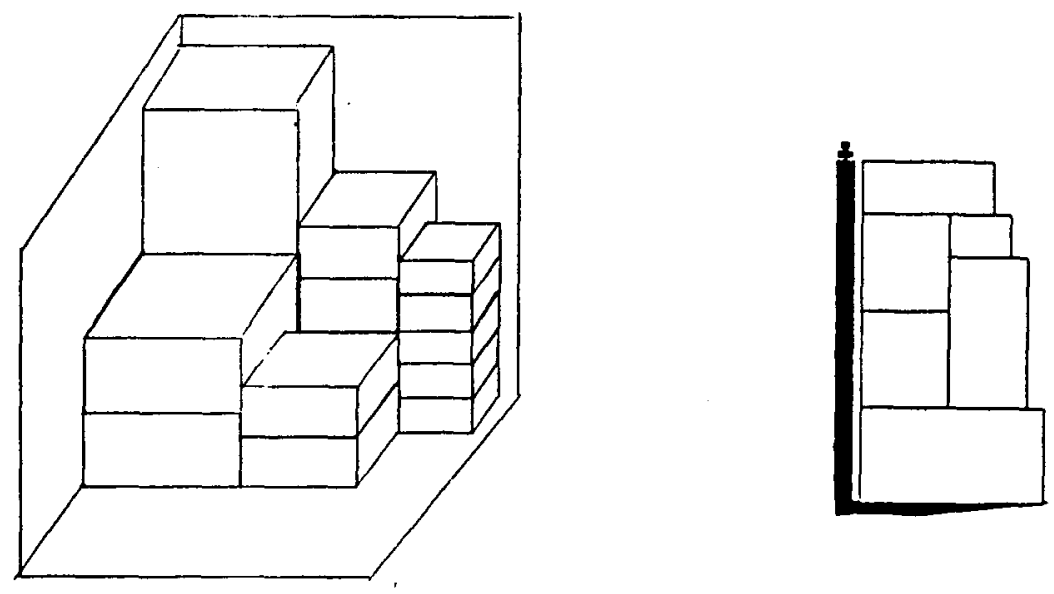

Figura 2.4: Problemas de corte tridimensional

\subsection{Caso tridimensional}

Para estudar peças tridimensionais a literatura tem se mostrado mais restrita, ainda que seja um caso muito comum. Um exemplo é o empacotamento de contêineres. Schneider[1988] ${ }^{3}$, citado por Morabito[1992], propôs um método exato e um método heurístico verificando que este último se comporta melhor na busca de soluções.

Morabito[1992] faz um amplo estudo de casos conhecidos abordando o problema para o carregamento de paletes e contêineres, veja a figura 2.4. A proposta é solucionar o problema através da representação dos padrôes em um grafo-E/OU. Esta abordagem é uma generalizaçâo de trabalhos anteriores para o caso bidimensional guilhotinado (veja Morabito[1989]). No capitulo 4 fazemos um estudo da abordagem em grafo-E/OU para o problema de corte.

\subsection{Caso multi-dimensional}

Quando falamos em padrâo de corte estamos nos referindo diretamente à distribuição de peças menores numa peça maior. O problema de alocar tarefas, visto como um problema de distribujção, tem o mesmo tratamento do problema de cortes.

Existem dois tipos de tarefas: tarefas que dependem uma da outra, e tarefas $i n-$

\footnotetext{
${ }^{3}$ SCHNEIDER, W. "The trim-loss minimization in a crepe-rubber mill: optimal solution versus heuristic in a 2(3)-dimensional case", European Journal of Operational Research 34, pp. 273-281.
} 


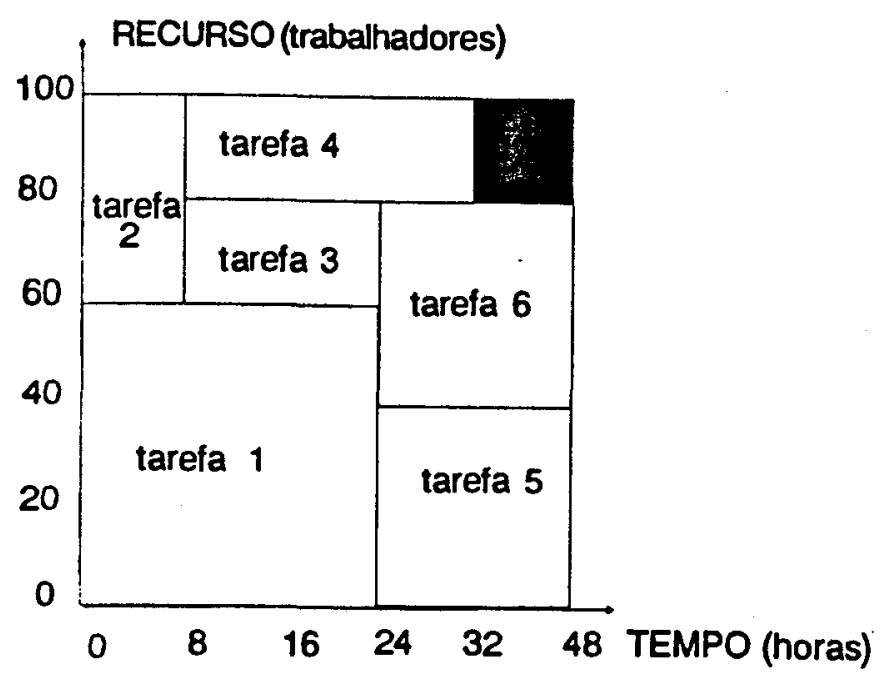

Figura 2.5: Corte multidimensional

dependentes. Por exemplo, numa indústria existe um grupo de funcionários para preparar peças e outro grupo para fazer a montagem delas. Neste caso esta última depende da primeira, assim elas são dependentes.

Consideremos que existem por dia $m$ tipos de recursos renováveis: $R_{1}$ recursos do tipo $1, R_{2}$ recursos do tipo $2, \ldots, R_{m}$ recursos do tipo $m$, $\mathrm{e} T$ horas disponíveis para executar $\mathrm{n}$ tarefas independentes. Cada tarefa $\mathrm{j}$ consome $\mathrm{r}_{1, j}$ recursos do tipo $1, \mathrm{r}_{2, j}$ recursos do tipo $2, \ldots, \mathrm{r}_{m, j}$ recursos do tipo $\mathrm{m}, \mathrm{j}=1,2, \ldots, \mathrm{n}$. O problema consiste em determinar qual é a forma de alocar n tarefas para que os dias gastos sejam o menor possivel. Considerando $m$ recursos, a solução estaria no espaço $R^{m+1}$, ou seja, este é um problema de alocação multi-dimensional.

A figura 2.5 representa um problema de alocar 6 tarefas independentes entre si, quando estão disponiveis 100 trabalhadores (um recurso), e $\mathrm{T}=48$ horas. Cada tarefa pode ser visualisada como sendo uma peça retangular bidimensional, onde a área sombreada representa a ociosidade do recurso.

A próxima parte aborda a bibliografia básica para o caso bidimensional nãoguilhotinado e a abordagem por grafo-E/OU para cortes guilhotinados, a qual será estendida para o caso não-guilhotinado. 


\section{Parte II}

\section{Revisão bibliográfica}




\section{Capítulo 3}

\section{Representação em grafo-E/OU}

Este capítulo faz a abordagem do problema de corte em grafo-E/OU. Apresentaremos as técnicas de redução para o grafo, passiveis de serem utilizadas para o caso não-guilhotinado.

\subsection{O grafo-E/OU}

Rich $^{1}$, citado por Morabito et al.[1990], descreve um grafo-E/OU como a estrutura de representaçâo de um problema que pode ser decomposto em um conjunto de subproblemas solucionáveis, cujas soluçôes podem ser compostas de forma a determinar uma soluçâo para o problema em questão.

Podemos representar o problema de encontrar um padrão de corte como um processo de busca num grafo-E/OU. A peça a ser cortada define um nó inicial e os cortes as ramificações de cada nó. No caso do corte guilhotinado, por exemplo, dois novos retângulos são produzidos a cada corte, correspondendo a dois novos problemas. $\mathrm{O}$ arco que aponta para estes dois novos nós chamamos arco-E.

A figura 3.1 mostra um exemplo de arco-E para o corte guilhotinado saindo do nó $\mathrm{A}$ e apontando para os dois nós sucessores $\mathrm{B}$ e $\mathrm{C}$. Uma vez encontradas as soluções para os retângulos $B$ e $C$, teríamos uma solução para $A$.

Morabito et al.[1991] implementaram com sucesso um algoritmo de resolução

\footnotetext{
${ }^{1}$ RJCH, E. (1983) - "Artificial intelligence", International Student Edition - McGraw-Hill
} 


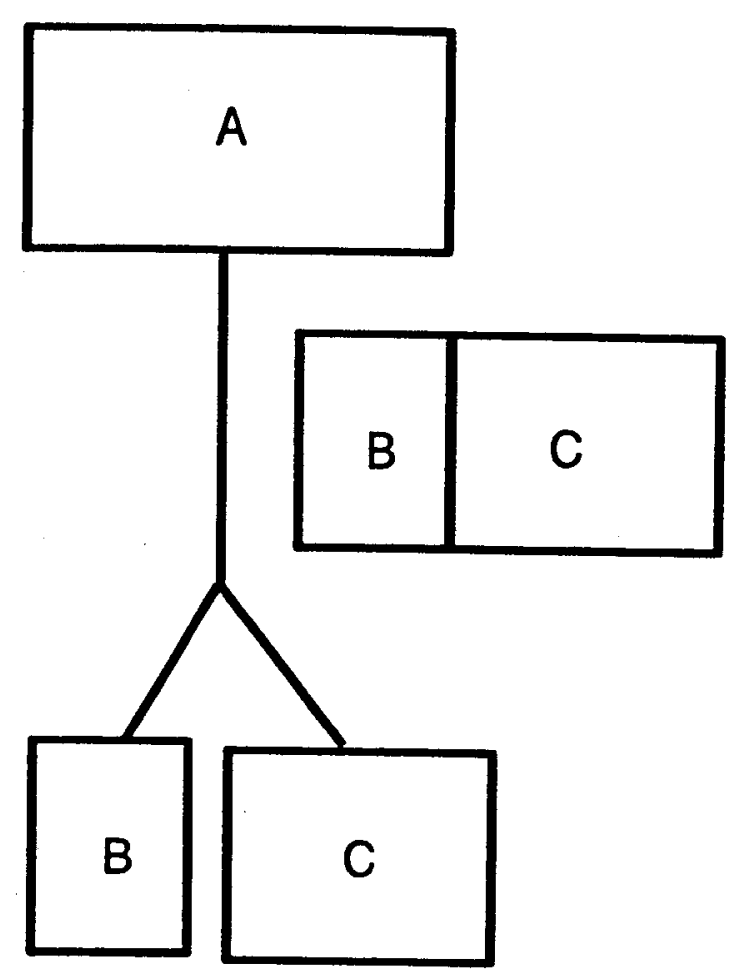

Figura 3.1: Arco-E para cortes guilhotinados.

do problema de corte bidimensional restritos ao corte guilhotinado, usando a técnica de busca em grafo-E/OU. Chamaremos os cortes guilhotinados também por não-guilhotinados de ordem 0.

Para cada retângulo podem existir várias possibilidades de corte, ou seja, diferentes arcos-E. Na figura 3.2 por exemplo, temos outros cortes para o mesmo retângulo A da figura 3.1. Existe um que representa a possibilidade do retângulo $A$ não ser cortado. Christofides \& Whitlock [1977] introduziram em todos os nós um corte chamado corte-0, representando esta possibilidade.

Pode-se escolher ou um arco-E ou outro, uma vez escolhido um arco, temos dois nós: o primeiro e o segundo, dai o nome grafo-E/OU. Uma vez cortado em dois retângulos, estes dois novos retângulos podem ser cortados em quatro novos retângulos, até que nos retângulos, o corte não se faz necessário. 


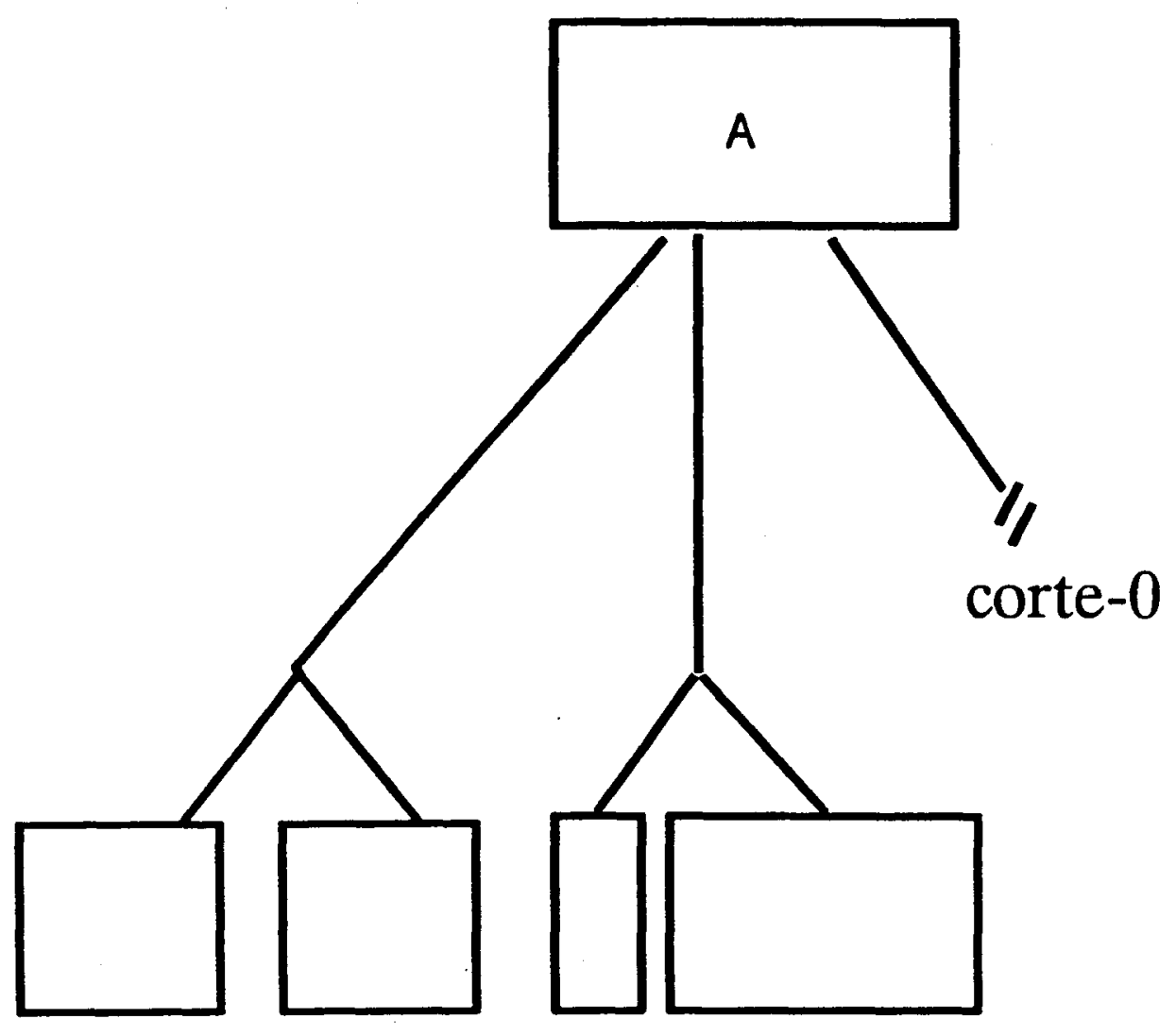

Figura 3.2: Outros arcos-E para o retângulo da figura 3.1. 
Classificaremos os nós como abertos e fechados. Os nós em que não é possível mais nenhuma expansâo chamamos de fechados, ou seja, todas as possibilidades de corte já foram investigadas, e caso contrário abertos.

Estendendo o grafo-E/OU para padrões não-guilhotinados de ordem 1 teremos arcos-E apontando para cinco novos nós, como mostra a figura 3.3.

Um caminho completo no grafo representa uma seqüência de cortes que terminará em uma ou mais peças retangulares, e então determina um padrão de corte, ou seja, uma soluşão factível para o problema irrestrito. Chamamos este caminho de hipercaminho. Por exemplo, a figura 3.4 mostra um padrão formado pela combinação de cortes não-guilhotinados de ordens $0 \mathrm{e} 1$, e o hiper-caminho que representa este padrão no grafoE/OU é mostrada na figura 3.5. Nos limitaremos a estudar o grafo-E/OU para padrões produzidos somente por cortes não-guilhotinados de ordem 0 e 1 .

$\mathrm{Na}$ prática, o grafo-E/OU torna-se muito grande, e por esta razão é necessário estabelecer regras na construção dos padrões factíveis, para evitar que nós sejam expandidos desnecessariamente, caso contrário este trabalho se torna muito caro computacionalmente. Abordaremos algumas técnicas de podas nas ramificaçoes desnecessárias do grafo-E/OU utilizadas nas literaturas para padrões guilhotinados.

\section{Simetria}

Christofides \& Whitlock[1977] fizeram uso de algumas propriedades já utilizadas por Herz[1972] para o corte guilhotinado a fim de eliminar algumas repetiçôes, uma delas é a simetria e o corte ordenado. Para analisar esta propriedade, consideremos um retângulo $\bar{A}=(\bar{L}, \bar{W})$, nele existem $\bar{L}+\bar{W}-2$ cortes possíveis (não estamos considerando a possibilidade de não cortar $\bar{A}$ ), podemos ver que nestes cortes há duplicação de padrões. Se cortamos $\bar{A}$ com um corte vertical em $x=a$ então esta ramificação obteremos dois retângulos $(a, \bar{W})$ e $(\bar{L}-a, \bar{W})$, que estarão repetidos no corte $x=\bar{L}-a$. Para evitar esta duplicação basta limitar os cortes verticais para $x \in\{1,2, \ldots,[\bar{L} / 2\rfloor\} \mathrm{e}$, analogamente os horizontais para $y \in\{1,2, \ldots,\lfloor\bar{W} / 2\rfloor\}$.

\section{Corte ordenado}

Para analisar o corte ordenado considere $x=a$, um corte vertical em $\bar{A}$.Temos dois novos retângulos $(\mathrm{a}, \bar{W})$ e $(\bar{L}-\mathrm{a}, \bar{W})$, e em um outro nó sucessor, $(\bar{L}-\mathrm{a}, \bar{W})$ é cortado em $x=b$, novamente com um corte vertical, assim obtemos três retângulos (a, $\bar{W}),(\mathrm{b}, \bar{W})$ e $(\bar{L}-\mathrm{a}-\mathrm{b}, \bar{W})$ a partir de $(\bar{L}, \bar{W})$. Estes três retângulos poderiam 


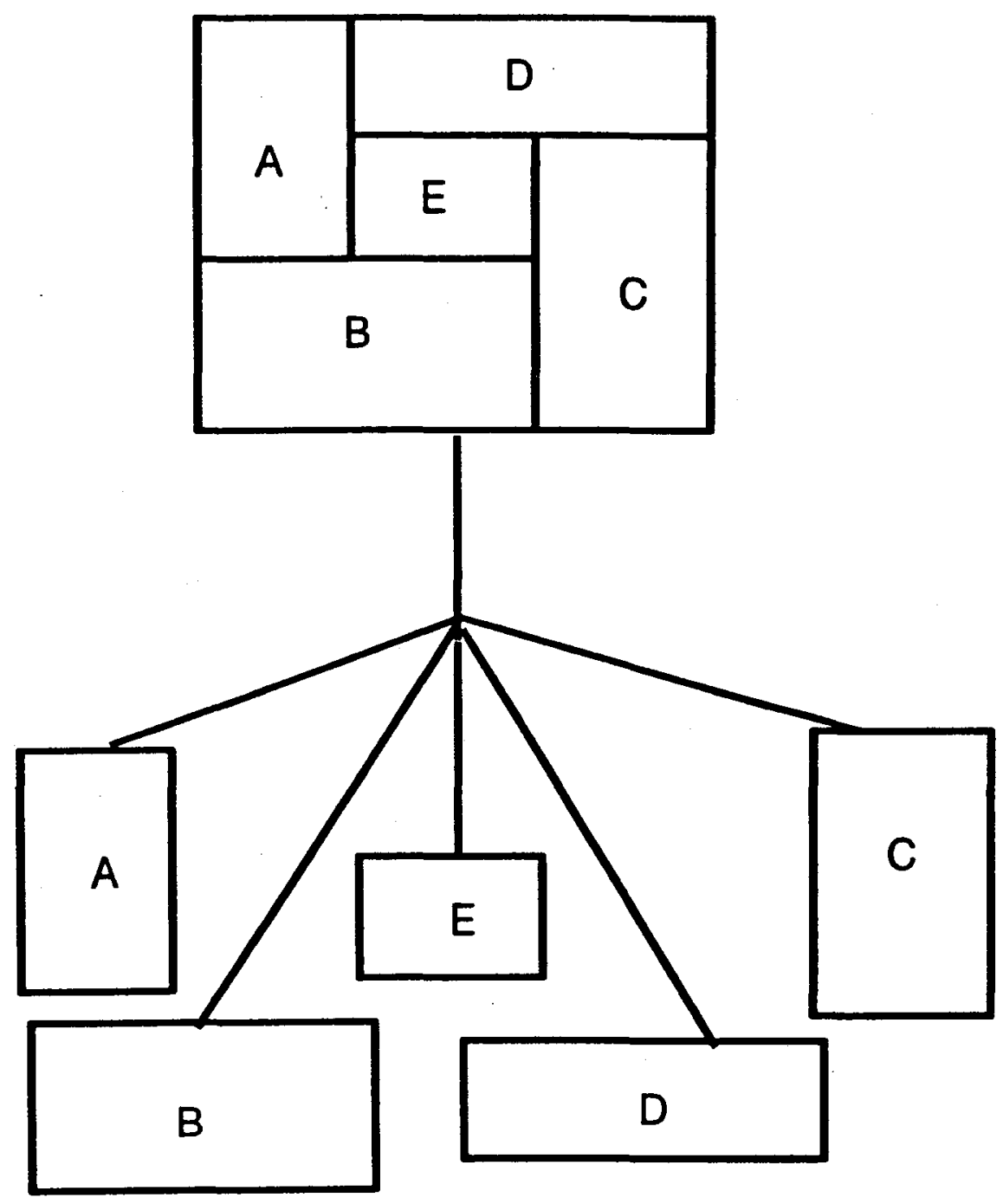

Figura 3.3: Arco-E para padrões não-guilhotinados de ordem 1

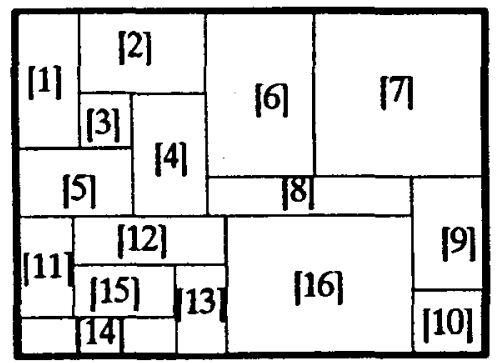

Figura 3.4: Padrão de corte que envolve apenas cortes não-guilhotinados de ordens 0 e 1 


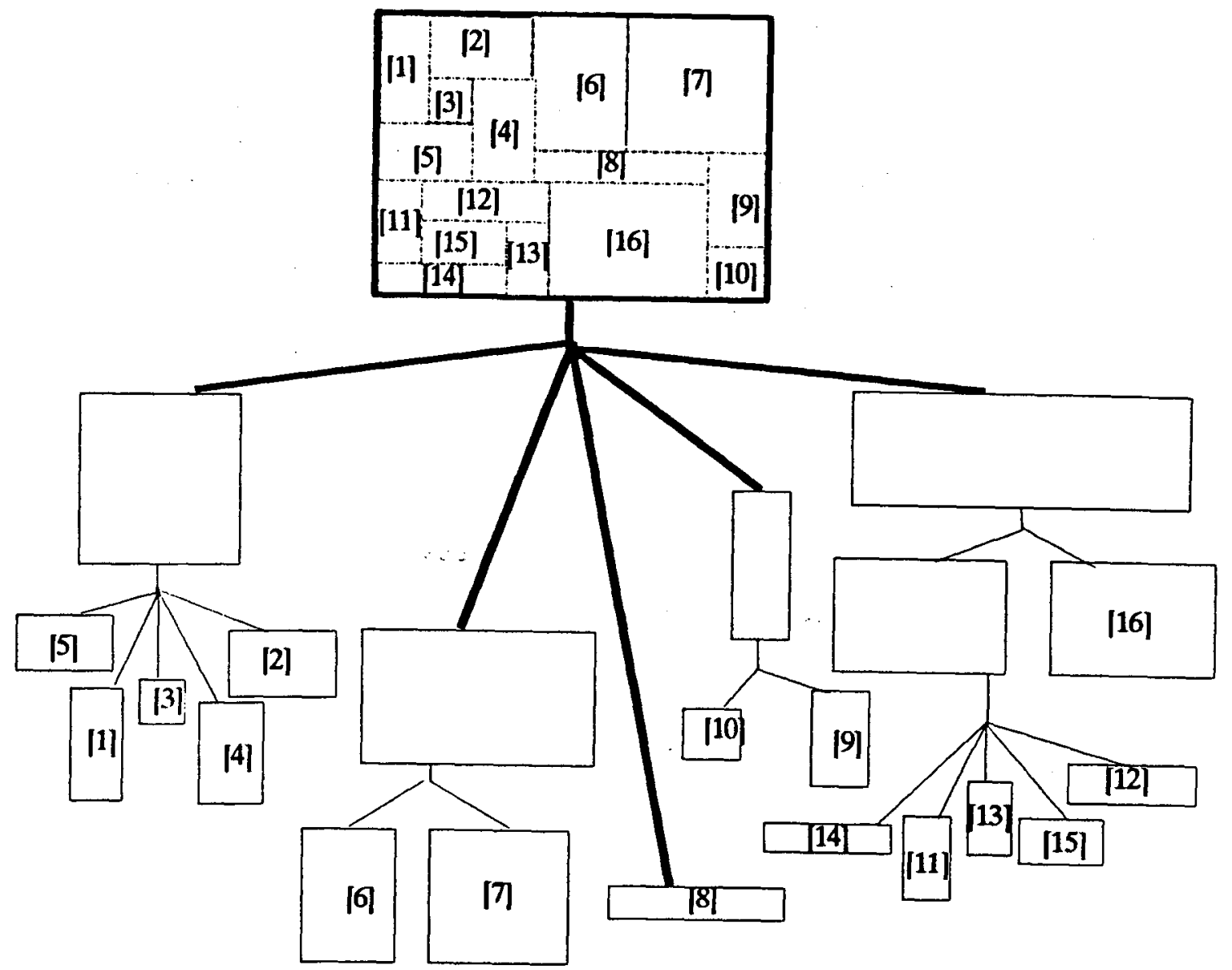

Figura 3.5: Grafo-E/OU para o padrâo de corte da figura 3.4
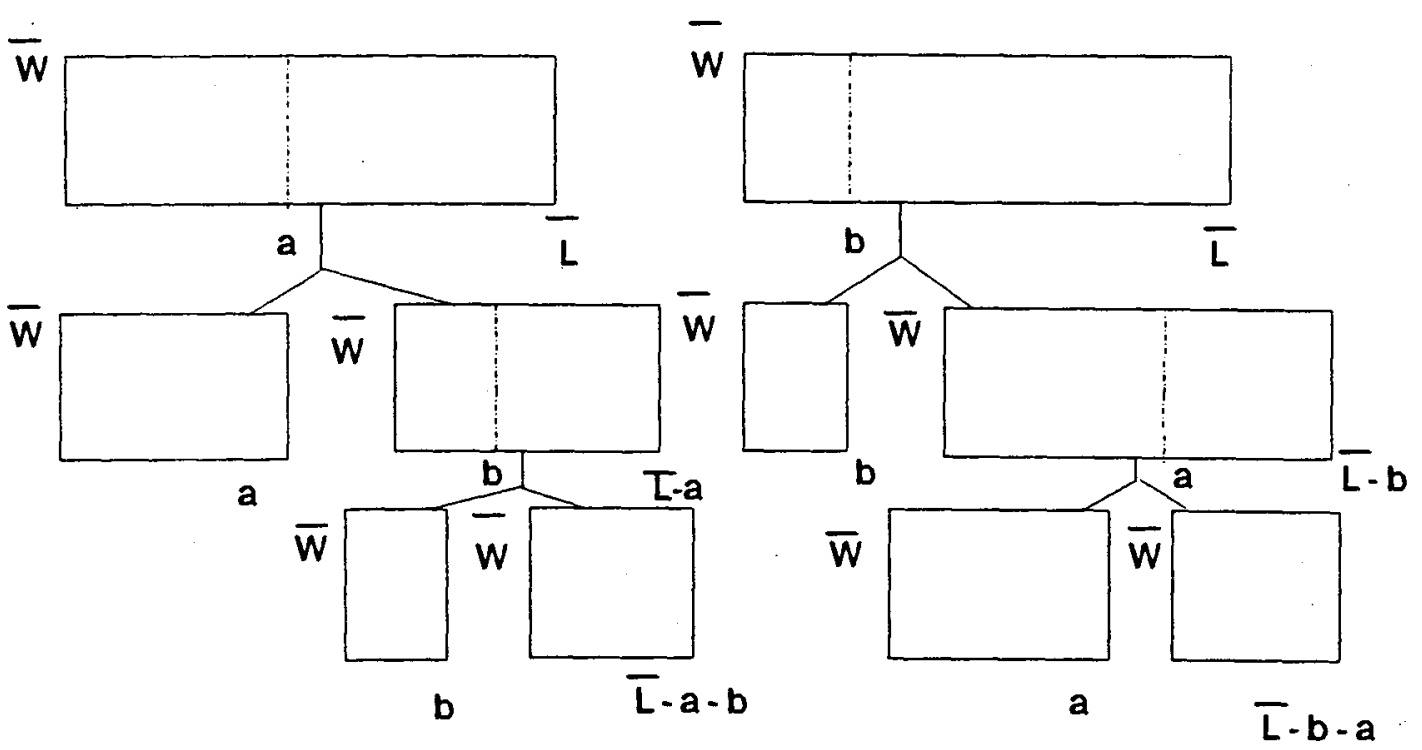

Figura 3.6: Padrão duplicado 


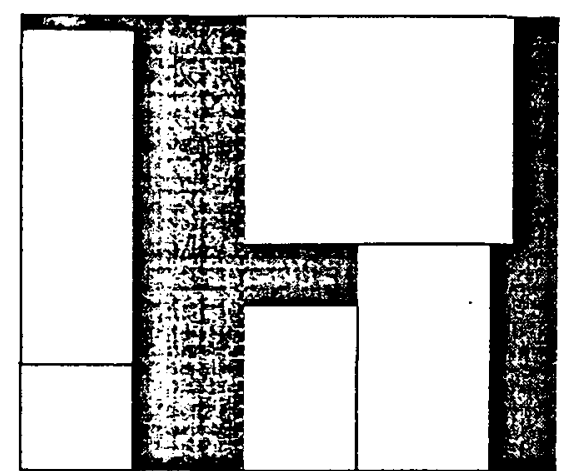

a'

(A) - padrão de corte nåo-normalizado

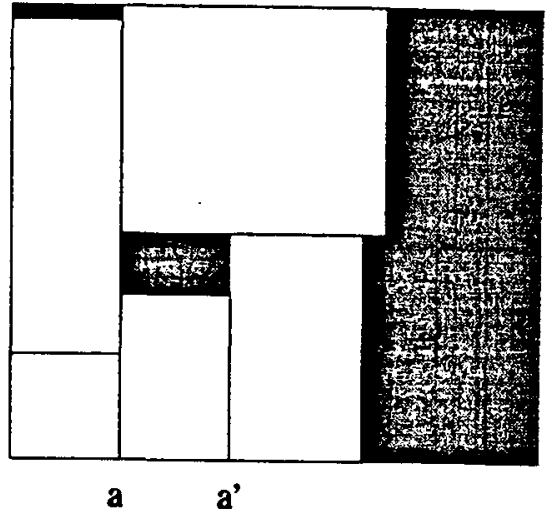

(B) - padrão normalizado

Figura 3.7: Padrões de cortes não normalizado (A) e normalizado (B)

ser obtidos se tivéssemos feito primeiro o corte em $x=b$ e $x=a \operatorname{em}(\bar{L}-\mathrm{b}, \bar{W})$, veja figura 3.6.

Este tipo de duplicação pode ser removida sem perder a otimalidade se um corte vertical é feito em $x=a$ e todos os cortes verticais subseqüentes forem maiores ou iguais à $a$. Juntando esta restriçâo à imposta pela simetria, concluímos que se para o maior dos retângulos resultantes, $(\bar{L}-a, \bar{W})$, a extensão dos cortes verticais é agora limitado para $x \in\{a, a+1, \ldots,\lfloor(\bar{L}-a) / 2\rfloor\}$, e se $\lfloor(\bar{L}-a) / 2\rfloor<a$ nenhum corte vertical além precisa ser feito. Para o menor, $(a, \bar{W})$, nenhum corte vertical deve ser realizado. De modo análogo para os cortes horizontais, se um corte é feito em $y=b$ no retângulo $(\bar{L}, b)$ só é necessário fazer cortes horizontais em $y \in\{b, b+1, \ldots,\lfloor(\bar{W}-b) / 2\rfloor\}$.

\section{Padrão normalizado}

O padrão normal foi usado primeiramente por Herz[19i2], que chamou de disscç̧ôes canônicas. Vamos definir primeiro o que é um padrào nâo normalizado, é aquele onde há pelo menos uma peça de encomenda onde suas margens inferior e esquerda 
nào estejam em contato com as margens inferior e esquerda de $A_{0}$ nem com as margens superior e direita de outra peça de encomenda. A figura 3.7 mostra dois padrões de cortes guilhotinados. Veja que o corte realizado no ponto a', figura (A), poderia ser feito apenas em $a<a^{\prime}$, figura (B), gerando o mesmo padrão.

É possivel limitar os cortes verticais e horizontais apenas para valores que levam a padróes normais. Por exemplo, para cortes verticais podemos considerar os pontos $\mathbf{x}$, que chamamos pontos de discretizaşão, que sejam alguma combinação dos comprimentos $l_{i}$ das peças de encomenda. Se temos um retângulo $\bar{A}=(\bar{L}, \bar{W})$ devemos então considerar as peças i tais que $w_{i} \leq \bar{W}$. Tomando as larguras $w_{i}$ ordenadas em ordem não decrescente, ou seja, $w_{1} \leq w_{2} \leq \ldots \leq w_{m}$, podemos assim limitar aos cortes em $x$ tal que $x \in X$ com:

$$
X=\left\{x / x=\sum_{i=1}^{k} \alpha_{i} l_{i}, x \leq\lfloor\bar{L} / 2\rfloor, \alpha_{i} \text { positivo e inteiro }\right\}
$$

onde $\mathrm{k}$ é tal que $w_{k}=\operatorname{maximo}_{i}\left\{w_{i} / w_{i} \leq \bar{W}\right\}$

Podemos calcular este conjunto através de um algoritmo de recursão, que mostramos a seguir. Consideramos agora a função booleana com valor verdade, se $x \in X$ e falso caso contrário. Vamos considerar o menor comprimento, $l_{\min }$, das $\mathrm{k}$ peças que estamos considerando para o conjunto $X$, ou seja, $l_{\min }=\min _{1 \leq i \leq k}\left\{l_{i}\right\}$. Inicialmente fazemos $\mathrm{F}(\mathrm{x})=$ verdade para todo $x=l_{i}, i=1,2, \ldots, k, \mathrm{e} \mathrm{F}(\mathrm{x})=$ falso para $x<l_{\min }$. Assim para os demais valores $\mathrm{x}, l_{\min }+1 \leq x \leq \bar{L}-1$, temos que $\mathrm{F}(\mathrm{x})$ é verdade se existe algum $\mathrm{i}, i=1,2, \ldots, k$, tal que $F\left(x-l_{i}\right)=$ verdade. Assim o conjunto $X$ pode ser construído para qualquer $\mathrm{x}$, percorrendo $\mathrm{F}(\mathrm{x})$ para $x \leq \bar{L}-1$.

É análogo a geração do conjunto correspondente aos cortes horizontais.

No capítulo seguinte nos referimos aos cortes sem restrição à guilhotina. 


\section{Capítulo 4}

\section{Programa linear 0-1 e cortes não guilhotinados}

Beasley[1985a] foi o primeiro a dar uma formulação matemática e a propor um algoritmo de resolução para o problema de corte bidimensional não-guilhotinado. Neste capítulo faremos uma abordagem desse estudo.

\subsection{Formulação matemática}

A formulação matemática elaborada para o problema bidimensional não guilhotinado por Beasley[1985a] é a que segue.

Consideremos uma peça retangular em estoque $A_{0}=\left(L_{0}, W_{0}\right)$, como na figura 4.1 , e m retângulos $A_{i}=\left(l_{i}, w_{i}\right)$, cada um com um valor $v_{i}$ associado, $i=1,2, \ldots, m$. Observamos que os valores $L_{0}, W_{0}, l_{i}, e w_{i}, \operatorname{com} i=1,2, \ldots, m$, são inteiros positivos e que $A_{0}$ é anisotrópico, e isto significa que, as peças $A_{i}, i=1,2, \ldots, m$, têm orientação fixa, ou seja, um retângulo $(\mathrm{u}, \mathrm{v})$ não é o mesmo que um retângulo $(\mathrm{v}, \mathrm{u})$, e suas margens devem ser cortadas paralelamente às margens de $A_{0}$. Consideremos ainda o conjunto de todos os pontos onde o canto inferior esquerdo de uma peça de encomenda poderia ser alocada: sejam $\left\{0,1, \ldots, L_{0}-1\right\}$ e $\left\{0,1, \ldots, W_{0}-1\right\}$ os conjuntos de discretização para os comprimentos e larguras, respectivamente, onde o canto inferior esquerdo de uma peça $A_{i}$ poderia ser alocada. A estes conjuntos pode ser aplicada a normalização, veja seção 3.1 . Assim, vamos considerar os conjuntos normalizados $\mathcal{L}$ e $\mathcal{W}$, onde $\mathcal{L} \subseteq\left\{0,1, \ldots, L_{0}-1\right\}$ e $\mathcal{W} \subseteq\left\{0,1, \ldots, W_{0}-1\right\}$. Definamos a seguinte variável de decisão: 


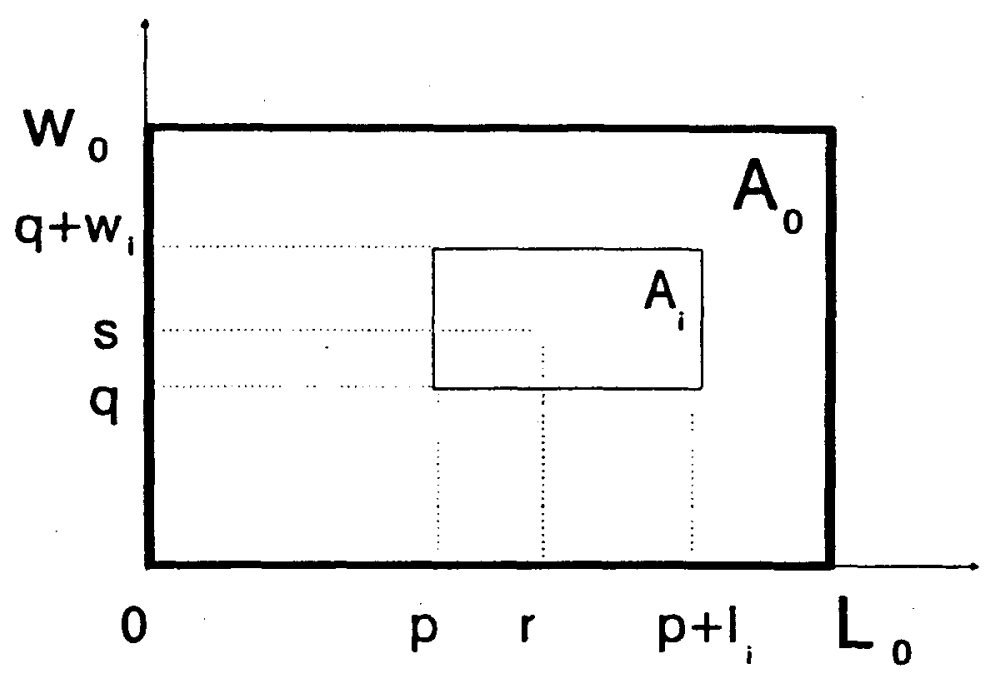

Figura 4.1: Alocação de uma peça através do corte não-guilhotinado

$$
x_{i p q}= \begin{cases}1 & \text { se a peça i é alocada com seu canto inferior esquerdo em }(\mathrm{p}, \mathrm{q}) . \\ 0 & \text { caso contrário. }\end{cases}
$$

com $p \in \mathcal{L}$, e $q \in \mathcal{W}$. Note que definindo a variável deste modo, estaremos tratando de um problema de programação inteira 0-1.

Para evitar a sobreposição de peças e para que nenhuma peça seja alocada com parte de sua área fora do retângulo $A_{0}=\left(L_{0}, W_{0}\right)$, consideraremos uma constante $a_{i p q r s}$ da seguinte maneira:

$$
a_{i p q r s}=\left\{\begin{array}{cc}
1 & \text { se } 0 \leq p \leq r \leq p+l_{i}-1 \leq L_{0}-1, \mathrm{e} \\
& 0 \leq q \leq s \leq q+w_{i}-1 \leq W_{0}-1 \\
0 & \text { caso contrário }
\end{array}\right.
$$

qualquer que seja $r \in \mathcal{L}$ e $s \in \mathcal{W}$, e estabeleçamos a seguinte relação:

$$
\sum_{i=1}^{m} \sum_{p \in \mathcal{L}} \sum_{q \in \mathcal{W}} a_{i p q r s} x_{i p q} \leq 1, \forall \mathrm{r} \in \mathcal{L} \mathrm{e} \forall \mathrm{s} \in \mathcal{W}
$$

ou seja, no ponto $(r, s)$ é cortada no máximo uma peça, veja figura 4.1.

Tomemos o seguinte exemplo. Sejam as peças de encomenda, $A_{1}=(2,1)$ e $A_{2}=$ $(3,3)$, com valores $v_{1}$ e $v_{2}$ associados a elas e uma peça em estoque $A_{0}=(4,3)$. Temos então $\mathcal{L}=\{0,2\}$ e $\mathcal{W}=\{0,1,2\}$. Observe que estes conjuntos estão normalizados. Para o ponto $(\mathrm{r}, \mathrm{s})=(2,1)$ temos que: $a_{\mathrm{ipg} 21}=1$ somente para $(\mathrm{i}, \mathrm{p}, \mathrm{q}) \in\{(1,2,1),(2,0,0)\}$. 


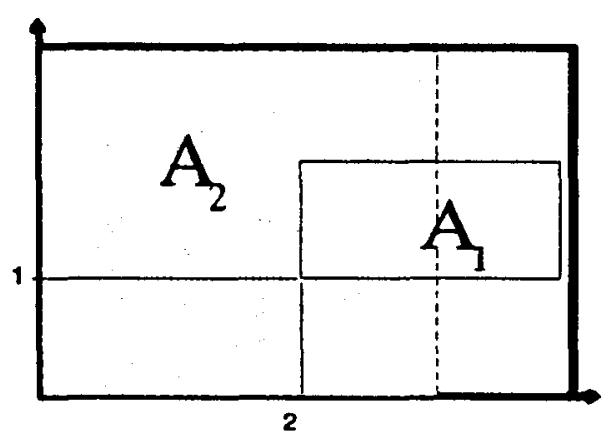

Figura 4.2: Sobreposição de peças no ponto $(2,1)$.

Assim substituindo em 4.1 temos que:

$$
x_{121}+x_{200} \leq 1 \text {. }
$$

Temos que optar em colocar a peça $A_{1}$ em $(2,1)$ ou $A_{2}$ em $(0,0)$. Veja a figura 4.2 , se assim nào fosse, teríamos mais de uma peça alocada em um mesmo ponto.

Suponhamos que existe um limitante inferior $P_{i}$ e um limitante superior $Q_{i}$ para cada peça $\mathrm{i}, i=1,2, \ldots, m$, ou seja:

$$
P_{i} \leq \sum_{p \in \mathcal{L}} \sum_{g \in \mathcal{W}} x_{i p q} \leq Q_{i}, i=1,2, \ldots, m .
$$

O problema então pode ser formulado por:

$$
\text { Maximize: } \sum_{i=1}^{m} \sum_{p \in \mathcal{L}} \sum_{q \in \mathcal{W}} v_{i} x_{i p q}
$$

s. à: 4.1 e 4.2

$$
x_{i p q} \in\{0,1\}, i=1,2, \ldots, m, \forall \mathrm{p} \in \mathcal{L} \text { e } \forall \mathrm{q} \in \mathcal{W} .
$$

onde 4.4 representa a restrição de integralidade.

Beasley[1985a] usou um procedimento tipo "branch-and-bound", numa busca em árvore binária, onde a variável de decisão $x_{i p q}$ pode ser somente 0 ou 1. Cada ramificação da árvore significa que existe um $x_{i p q}=1$, ou seja, uma peça do tipo i está alocada no ponto $(p, q)$, veja figura 4.1. Ele fez uso principalmente da combinação da relaxação 
lagrangeana para obter limitantes e do método do subgradiente para a melhoria de tais limitantes.

\section{Limitante lagrangeano}

ou seja:

Primeiro, tomamos a restrição 4.1 e abrimos todas possibilidades para $r \in \mathcal{L}$,

$$
\left.\begin{array}{rc}
(r=0, s) & \sum_{i=1}^{m} \sum_{p \in \mathcal{L}} \sum_{q \in \mathcal{W}} a_{i p q r s} x_{i p q}-1 \leq 0 \\
(r=1, s) & \sum_{i=1}^{n} \sum_{p \in \mathcal{L}} \sum_{q \in \mathcal{W}} a_{i p q r s} x_{i p q}-1 \leq 0 \\
\vdots & \\
\left(r=L_{0}-1, s\right) & \sum_{i=1}^{m} \sum_{p \in \mathcal{L}} \sum_{q \in \mathcal{W}} a_{i p q r s} x_{i p q}-1 \leq 0
\end{array}\right\} \forall s \in \mathcal{W}
$$

Fazendo a adição dessas desigualdades para todos $r \in \mathcal{L}$ temos:

$$
\sum_{r \in \mathcal{L}}\left\{\sum_{i=1}^{m} \sum_{p \in \mathcal{L}} \sum_{g \in \mathcal{W}} a_{i p q r s} x_{i p q}-1\right\} \leq 0, \quad \forall s \in \mathcal{W}
$$

ou seja,

$$
\sum_{r \in \mathcal{L}} \sum_{i=1}^{m} \sum_{p \in \mathcal{L}} \sum_{q \in \mathcal{W}} a_{i p q r s} x_{i p q} \leq|\mathcal{L}| \quad \forall s \in \mathcal{W}
$$

Se abrirmos as possibilidades para $s \in \mathcal{W}$ e fizermos a adição, teremos então:

$$
\sum_{s \in \mathcal{W}} \sum_{i=1}^{m} \sum_{p \in \mathcal{C}} \sum_{q \in \mathcal{W}} a_{i p q r s} x_{i p q} \leq|\mathcal{W}|, \quad \forall r \in \mathcal{L}
$$

Note que antes tínhamos $|\mathcal{L} \| \mathcal{W}|$ restriçōes e agora temos $|\mathcal{L}|+|\mathcal{W}|(|\mathcal{L}|$ e $|\mathcal{W}|$ são os números de elementos de $\mathcal{L}$ e $\mathcal{W}$, respectivamente). Se uma solução satisfaz as restriçôes em 4.1 também satisfaz 4.5 e 4.6; e se considerarmos apenas as restrições 4.5 e 4.6 nos deparamos numa relaxação do problema.

Introduzindo os multiplicadores de Lagrange $g_{s} \geq 0$, com $s \in \mathcal{W}$, para restrição 4.5 e $h_{r} \geq 0$, com $r \in \mathcal{L}$, para restrição 4.6 , podemos então obter o problema lagrangeano: 


$$
\operatorname{maximize} \sum_{i=1}^{m} \sum_{p \in \mathcal{L}} \sum_{g \in \mathcal{W}} V_{i p q} x_{i p q}+\sum_{s \in \mathcal{W}} g_{s}|\mathcal{L}|+\sum_{r \in \mathcal{L}} h_{r}|\mathcal{W}|
$$

onde:

s.à: 4.2 e 4.4

$$
V_{i p q}=v_{i}-\sum_{r \in \mathcal{L}} \sum_{s \in \mathcal{W}}\left(g_{s}+h_{r}\right) a_{i p q r s} .
$$

Este problema pode ser resolvido em $m$ subproblemas:

$$
\operatorname{maximize} \sum_{p \in \mathcal{L}} \sum_{q \in \mathcal{W}} V_{i p q} x_{i p q}+\sum_{s \in \mathcal{W}} g_{s}|\mathcal{L}|+\sum_{r \in \mathcal{L}} h_{r}|\mathcal{W}|
$$

s.à: 4.2 e 4.4

Seja $\left(X_{i p q}\right)$ o valor correspondente à solução do problema relaxado. Esta solução dá um valor para a função objetivo,que chamamos $\mathcal{Z}_{U \mathcal{B}}$, onde:

$$
\mathcal{Z}_{\mathcal{L B}}\left(g_{s}, h_{r}\right)=\sum_{i=1}^{m} \sum_{p \in \mathcal{L}} \sum_{q \in \mathcal{W}} V_{i p q} X_{i p q}+\sum_{s \in \mathcal{W}} g_{s}|\mathcal{L}|+\sum_{r \in \mathcal{L}} h_{r}|\mathcal{W}|
$$

mas que pode não representar uma solução factivel para o problema original já que a restrição das peças foi relaxada.

Para melhorar este limitante, Beasley[1985a] aplicou o método subgradiente ${ }^{1}$ em relação aos multiplicadores, ou seja, minimizou $\mathcal{Z}_{\mathcal{U B}}\left(g_{s}, h_{r}\right)$.

\section{Testes de redução}

Beasley[1985a] também usou outras formas de redução da árvore, por exemplo, em relação a sobreposiçâo de peças, ele faz a seguinte observação. Supondo que temos duas peças, digamos i e $\mathrm{j}$, tal que $l_{i}+l_{j}>L_{0}$, ou seja, elas não podem ser cortadas na mesma largura. Entâo podemos alterar $Q_{i}$, que é o número máximo de peças do tipo i que podem ser cortadas de $A_{0}$ por:

$$
Q_{i}=\min \left\{Q_{i},\left\lfloor L_{0} / l_{i}\right\rfloor\left\lfloor\left(W_{0}-\left\lceil P_{j} /\left\lfloor L_{0} / l_{j}\right\rfloor\right\rceil w_{j}\right) / w_{i}\right\rfloor\right\},
$$

e ainda outras formas de redução, como o que ele chamou de área livre, ou seja, a área ocupada por uma solução factível em $A_{0}$ será no mínimo $\sum_{j=1}^{m} P_{j} l_{j} w_{j}$, podemos ter então:

$$
Q_{i}=\min \left\{Q_{i}, P_{i}+\left\lfloor\left(L_{0} W_{0}-\sum_{j=1}^{m} P_{j} l_{j} w_{j}\right) /\left(L_{i} W_{i}\right)\right\rfloor\right) .
$$

\footnotetext{
${ }^{1}$ Veja Apéndice $A$
} 
Foram usados outros testes de redução: valor livre, penalidade sobre o número de peças cortadas, penalidade das posições cortadas e o problema da área.

Este modelo dado por Beasley[1985a] não será mais explorado nos próximos capítulos, onde procuraremos abordar o problema não guilhotinado como um processo de busca em grafo. O capítulo seguinte aborda o problema baseada na teoria dos grafos dada por Biró \& Boros[1984]. 


\section{Capítulo 5}

\section{Fluxos em rede no caso não-guilhotinado}

Neste capítulo apresentamos o problema não-guilhotinado utilizando a representação de fluxos em rede. Para tal são necessários alguns conhecimentos sobre teoria dos grafos.

\subsection{Peças em estoque do tipo "bobina"}

$\mathrm{Na}$ confeç̧ão de roupas é comum peças de tecidos serem armazenadas em "rolos", ou "bobinas", como mostra a figura 5.1. Estas peças devem ser cortadas em peças menores para montagem das roupas.

Mostraremos como é possível representar um padrão de corte para peças em estoque deste tipo. Chamaremos esta peça simplesmente por bobina, e utilizaremos conceitos básicos da teoria dos grafos. Esta abordagem é encontrada em Biró \& Boros[1984].

Definição 11 (Peça 1,5-dimensional) Uma peça que tenha duas dimensões e uma delas é variável é classificada como 1,5-dimensional (Hinxman[1980, citado por Morabito[1992]).

Uma bobina é 1,5-dimensional pois tem comprimento fixo e largura variável.

\footnotetext{
${ }^{1}$ HINXMAN, A." The trim-loss and assortment problems: a survey". EJOR 5, 1980, pp. 8-18.
} 

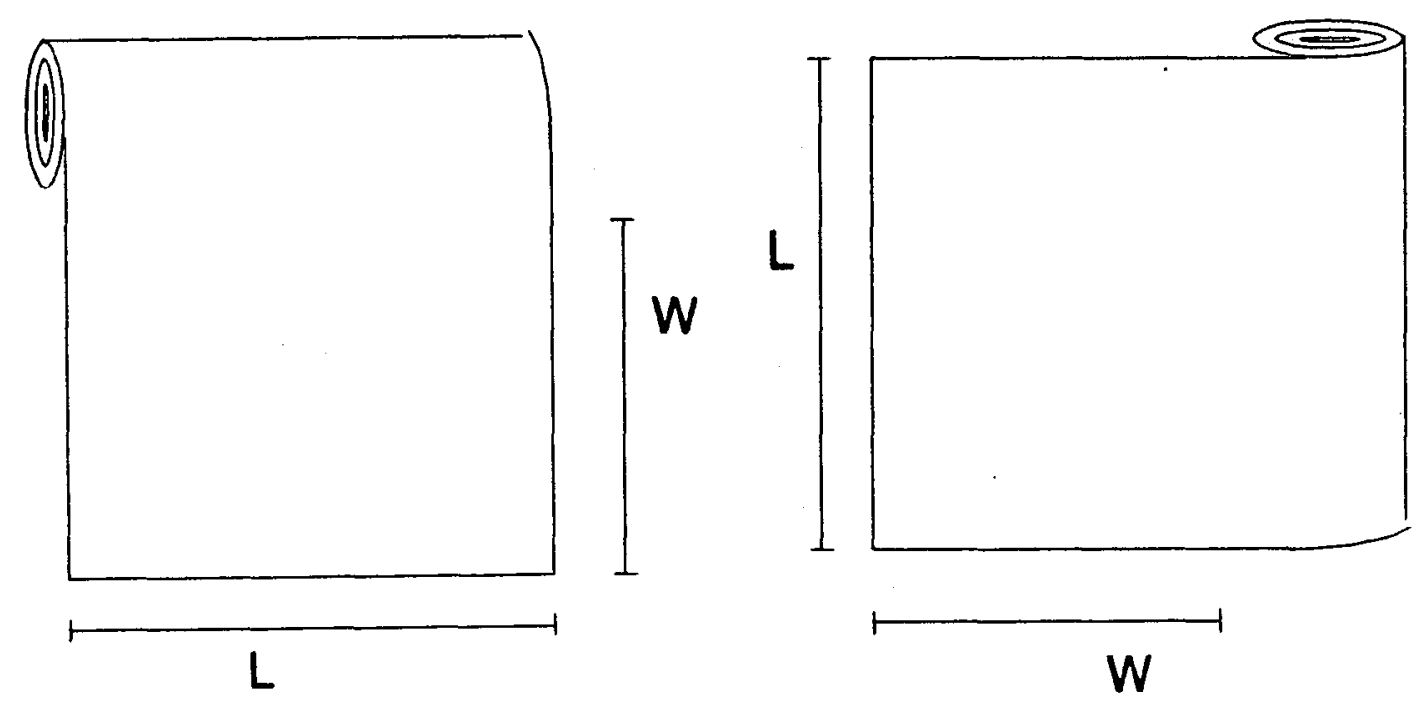

Figura 5.1: Peças em estoque do tipo bobina.

Consideremos um retângulo obtido da bobina de comprimento $L$ fixo e largura $\mathrm{W}$ variável e $\mathrm{m}$ retângulos $R_{i}=\left(l_{i}, w_{i}\right)$. O problema consiste em cortar exatamente uma vez cada peça $R_{i}$ procurando utilizar o minimo da largura W. Nos restringiremos a cortes ortogonais e permitiremos cortes não-guilhotinados. Vamos tomar a largura e o comprimento com orientação vertical e horizontal, respectivamente.

Definição 12 (Rede- $\mathcal{R}$ ) Considercmos o conjunto $R=\left\{R_{1}, R_{2}, \ldots, R_{m}\right\}$ e uma bobina de comprimento L. Uma Rede-R é uma rede com $m+2$ nós $\left(r_{0}, r_{1}, \ldots, r_{m}, r_{\infty}\right)$ $e$ arestas $a_{i, j}$, unindo os nós $r_{i} \in r_{j}$, com capacidade $c_{i, j}$ definida por:

$$
\left\{\begin{array}{l}
c_{i, j}:=c_{j, i}:=\min \left\{l_{i}, l_{j}\right\}, 1 \leq i \neq j \leq m \\
c_{0, j}:=c_{j, \infty}:=l_{j}, j:=1,2, \ldots, m \\
c_{0, \infty}:=L \\
c_{i, j}=0 \text { para os demais valores de } \mathrm{i} \mathrm{e} \mathrm{j}
\end{array}\right.
$$

Os nós $r_{0}$ e $r_{\infty}$ representam dois retângulos imaginários $R_{0}$ e $R_{\infty}$, respectivamente, que precedem e seguem o padrão de corte na bobina. A capacidade de um arco é a medida horizontal máxima (comprimento) ao longo do qual um retângulo pode ficar sob o outro, retângulos estes representados pelos nós unidos por este arco. A distância entre os retângulos não é levada em consideração desde que não haja sobreposição dos retângulos. 

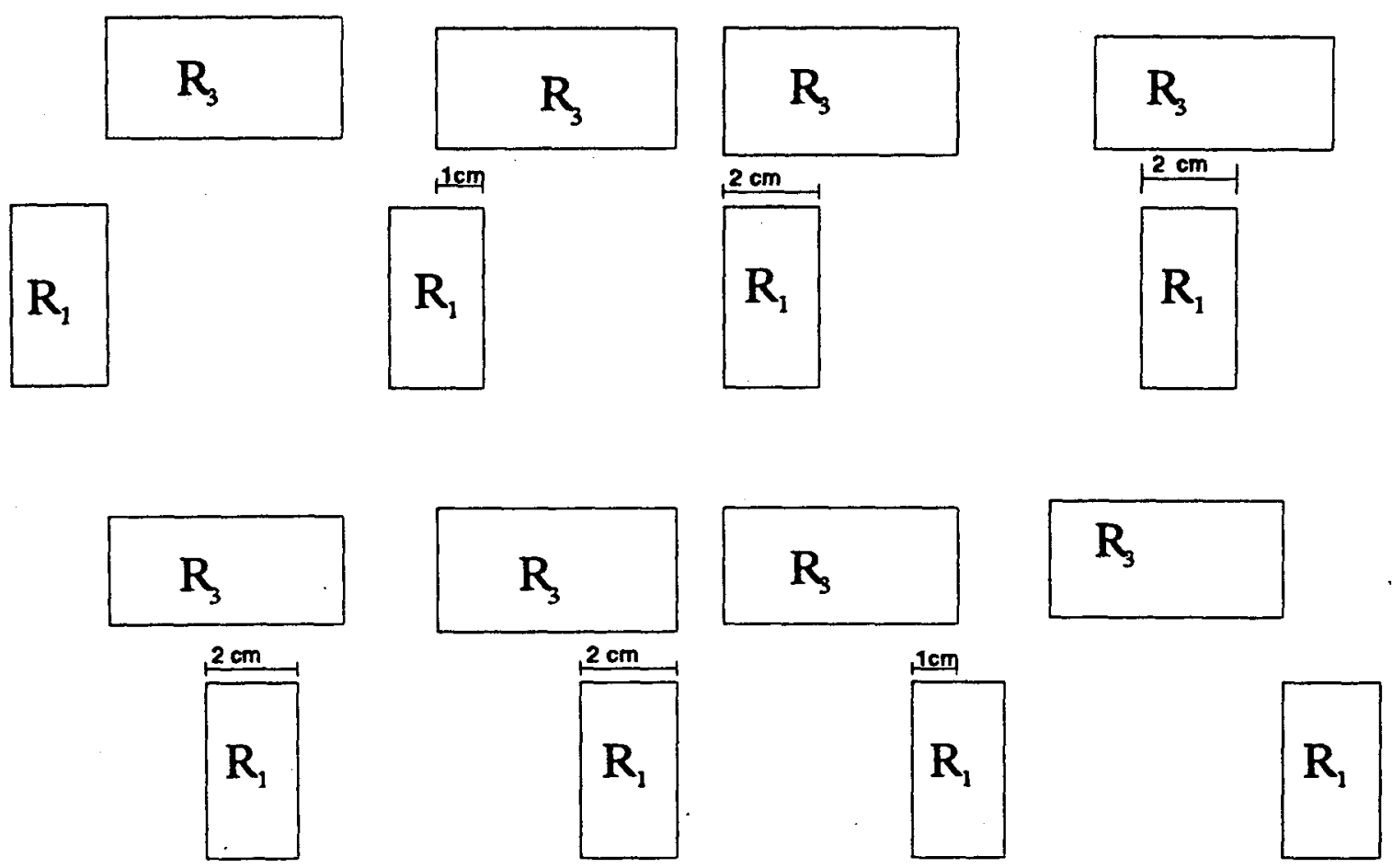

OBSERVĀCAO:

O máximo que $R_{1}$ pode ficar sob $R_{3}$ é o seu comprimento $1_{1}=2 \mathrm{~cm}$.

Figura 5.2: Capacidades $c_{i, j}$ relativos a $R_{1}$ e $R_{3}$ 


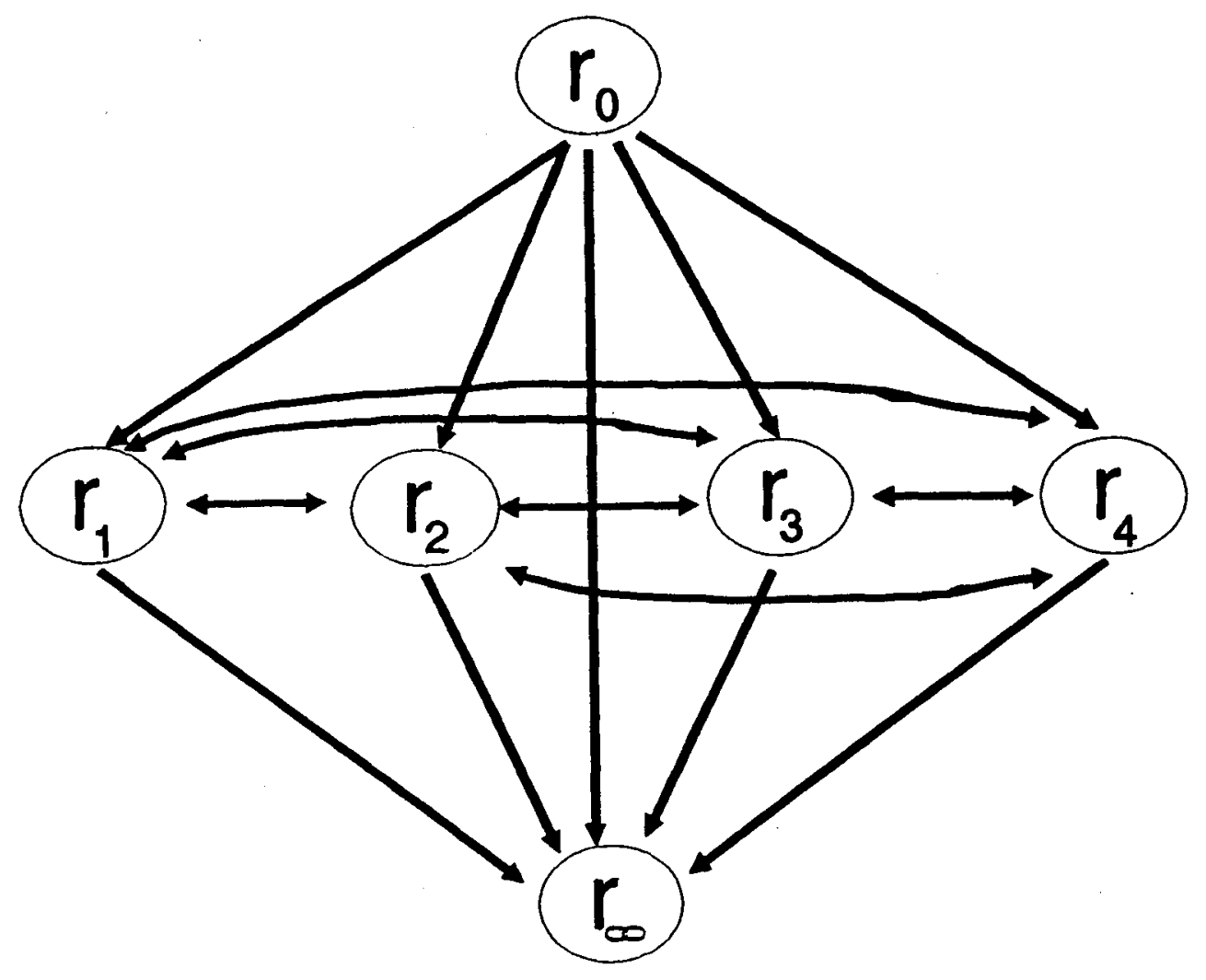

Figura 5.3: Rede- $R$ para o conjunto $R=\left\{R_{1}, R_{2}, R_{3}, R_{4}\right\}$

Considere um conjunto $R=\left\{R_{1}=(2,3), R_{2}=(3,2), R_{3}=(5,2), R_{4}=(4\right.$, 3)\} que deve ser cortado numa bobina de comprimento $L=8$. Na figura 5.2 vemos todas as possibilidades da peça $R_{1}$ ficar sob $R_{3}$. Note que não há sobreposição das peças e a medida máxima que $R_{1}$ pode ficar sob $R_{3}$ é seu comprimento $l_{1}$. A tabela a seguir mostra o valor das capacidades $c_{i, j}$ de cada aresta do conjunto $R$.

\begin{tabular}{|c|c|c|c|c|c|c|}
\hline \multicolumn{7}{|c|}{ Capacidade $c_{i, j}$} \\
\hline $\bar{i} \mathrm{j}$ & 0 & 1 & 2 & 3 & 4 & $\infty$ \\
\hline 0 & 0 & 2 & 3 & 5 & 4 & 8 \\
\hline 1 & 0 & 0 & 2 & 2 & 2 & 2 \\
\hline 2 & 0 & 2 & 0 & 3 & 3 & 3 \\
\hline 3 & 0 & 2 & 3 & 0 & 4 & 5 \\
\hline 4 & 0 & 2 & 3 & 4 & 0 & 4 \\
\hline$\infty$ & 0 & 0 & 0 & 0 & 0 & 0 \\
\hline
\end{tabular}

Note que a capacidade $c_{i, 0}$ é nula, isto significa que não é possível ir de $r_{i}$ para $r_{0}$, nem de $r_{\infty}$ para $r_{i}$ e nem de $r_{i}$ para $r_{i}, \forall \mathrm{i}$. A rede- $\mathcal{R}$ para o conjunto $R$ é dada na 


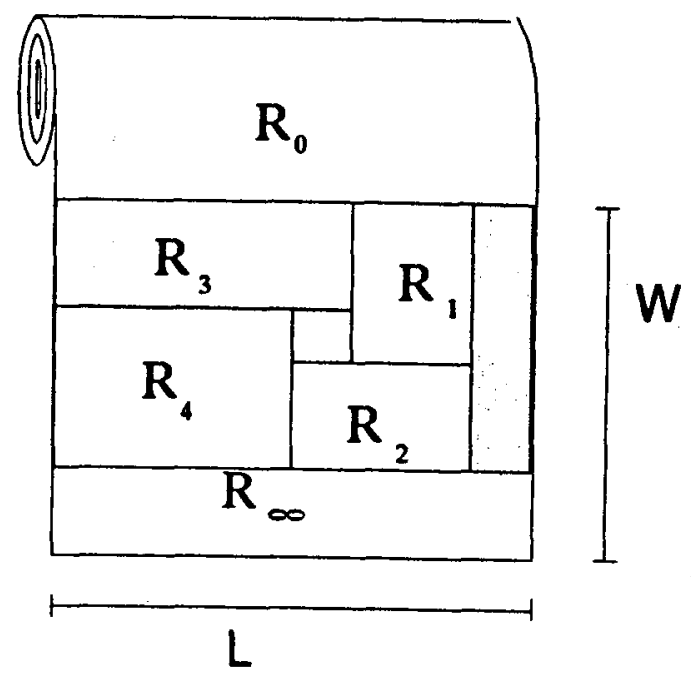

Figura 5.4: Padrão P para a bobina de comprimento 8 e $R$.

figura 5.3

Definição 13 (Fluxo- $\mathcal{R} \mathcal{P}$ ) Considere um conjunto $R$ e um padrão $P$ para uma bobina de comprimento $L$. O fluxo-RP em um anco $\left(r_{i}, r_{j}\right)$ da rede- $\mathcal{R}$ é a medida ao longo do qual o retângulo $R_{j}$ está diretamente sob $R_{i}$, ou seja, não existe nenhum retângulo entre eles.

Se o fluxo $f\left(r_{i}, r_{j}\right)$ que vai de $r_{i}$ para $r_{j}$ for positivo, isto significa que $R_{j}$ está sob $R_{i}$ e caso contrário $R_{i}$ está sob $R_{j}$. Na figura 5.4 temos um padrão $\mathrm{P}$ para o conjunto $R$ e a bobina de comprimento $L=8$. Observe que abaixo do retângulo imaginário $R_{0}$ estão os retângulos $R_{3}, R_{1}$ e $R_{\infty}$. Assim temos três arcos, $\left(r_{0}, r_{3}\right),\left(r_{0}, r_{1}\right)$ e $\left(r_{0}, r_{\infty}\right)$ com fluxos $5,2,1$, respectivamente. A representação deste padrão através do fluxo na rede- $\mathcal{R}$ está na figura 5.5 .

Definição 14 (Grafos isomorfos) Se, dados dois grafos, $G_{1}=\left(V_{1}, E_{1}\right) e G_{2}=\left(V_{2}, E_{2}\right)$, com $\left|V_{1}\right|=\left|V_{2}\right|=n$, existe uma função univoca $f: V_{1} \rightarrow V_{2}$, tal que $(v, w) \in E_{1}$ se e somente se $(f(v), f(u)) \in E_{2}, \forall v, u \in V_{1}$, então $G_{1}$ e $G_{2}$ são ditos isomorfos entre si.

Definição 15 (Grafo- $\mathcal{R P}$ ) Um grafo $G=(V, E)$ é dito grafo- $\mathcal{R P}$ se existem uma rede$\mathcal{R}$ para um conjunto $R$ e um fluxo-RP tal que o conjunto de vértices e o conjunto de arestas com fluxo positivo na rede-R formam um grafo isomorfo a $G^{\prime}=\left(V, E^{\prime}\right)$ onde $E=$ $E^{\prime} \cup\left\{r_{0}, r_{\infty}\right\}$, ou seja, $E=\left\{r_{1}, r_{2}, \ldots, r_{m}\right\} \cup\left\{r_{0}, r_{\infty}\right\}$ 


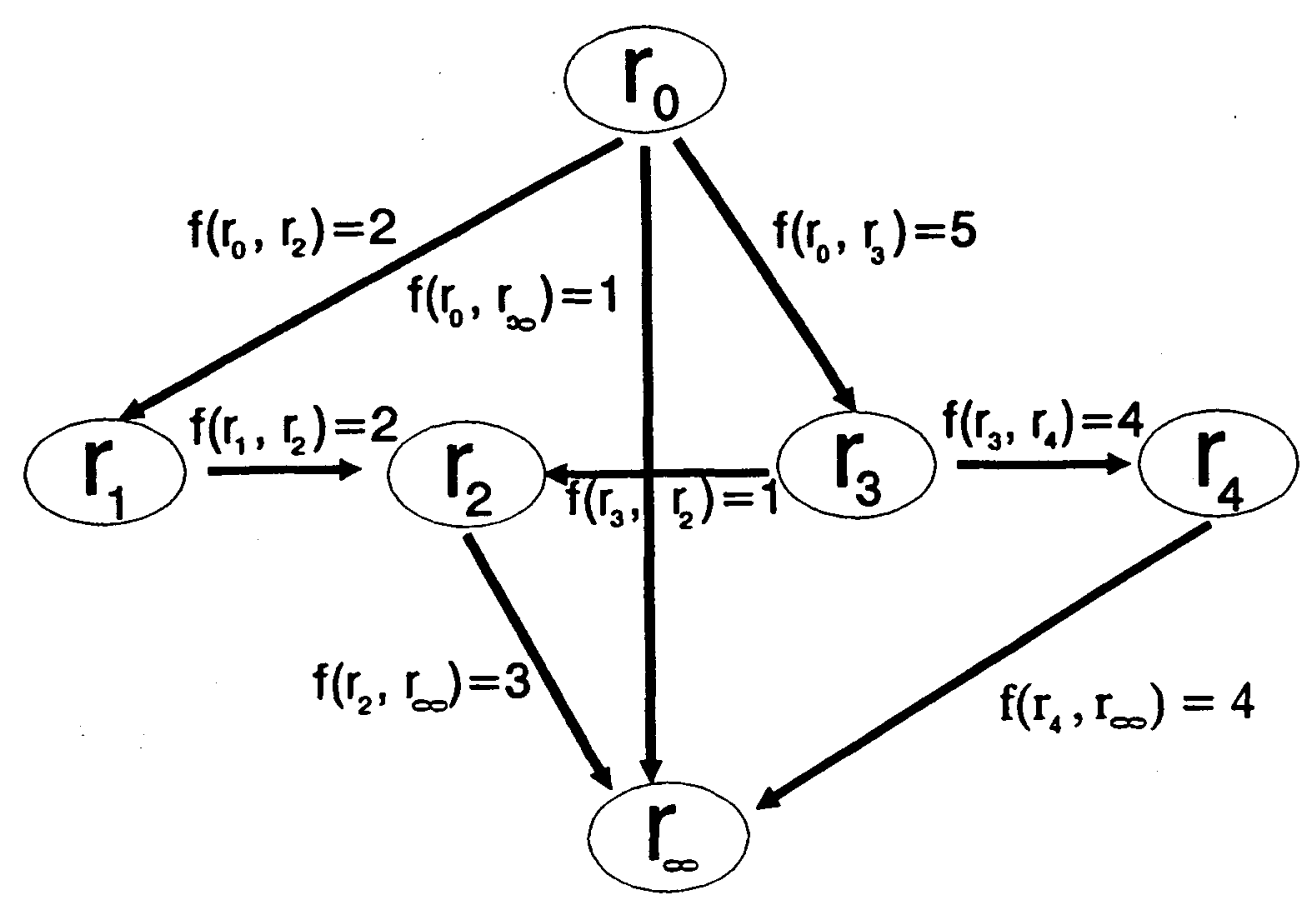

Figura 5.5: Representação do fluxo do padrão $\mathrm{P}$ na Rede- $\mathcal{R}$. 
O grafo- $\mathcal{R} \mathcal{P}$ descreve a estrutura de posicionamento, superior e inferior, das peças em um padrão de corte $P$ para o conjunto $R$. Podemos observar que qualquer padrão $P$ factivel pode ser representado por um fluxo- $\mathcal{R} \mathcal{P}$. Esta abordagem inovadora pode ser encontrada com mais detalhes em Biró \& Borós [1984], onde existe um algoritmo para determinar um padrão $\mathrm{P}$ para o problema definido neste capítulo.

A seguir, o próximo capítulo apresenta uma proposta de resolução para o problema bidimensional não-guilhotinado. 


\section{Parte III}

Proposta de resolução para o caso bidimensional não-guilhotinado 


\section{Capítulo 6}

\section{Cortes não-guilhotinados no grafo-E/OU}

Neste capítulo apresentamos a proposta de como abordar o problema de corte bidimensional regular não-guilhotinado e irrestrito através do grafo-E/OU.

Inicialmente vamos considerar uma placa retangular $A_{0}=\left(L_{0}, W_{0}\right)$ e m objetos, também retangulares, $A_{i}=\left(L_{i}, W_{i}\right)$ com um valor de utilidade $v_{i}$ associado a cada um. Devemos encontrar um padrão de corte tal que a somatória dos valores dos retângulos produzidos por ele seja o maior possivel.

Vamos nos restringir aos cortes não-guilhotinados de ordens 0 e 1.

Primeiro apresentaremos a solução restrita à guilhotina e a seguir ao corte não-guilhotinado de ordens 0 e 1 .

\subsection{Cortes não-guilhotinados de ordem 0}

Considere a abordagem em grafo-E/OU para o caso guilhotinado como dada no capítulo 3. Para efeito de ilustração, vamos considerar o seguinte exemplo. Sejam $A_{0}$ $=(7,5), A_{1}=(5,2)$ e $A_{2}=(2,3)$ com valores de utilidade $v_{1}=10$ e $v_{2}=6$, relativos às áreas dos retângulos $A_{1}$ e $A_{2}$, respectivamente. A figura 6.1 mostra como fica o grafo$\mathrm{E} / \mathrm{OU}$ para este problema considerando somente os cortes guilhotinados. Observe que 


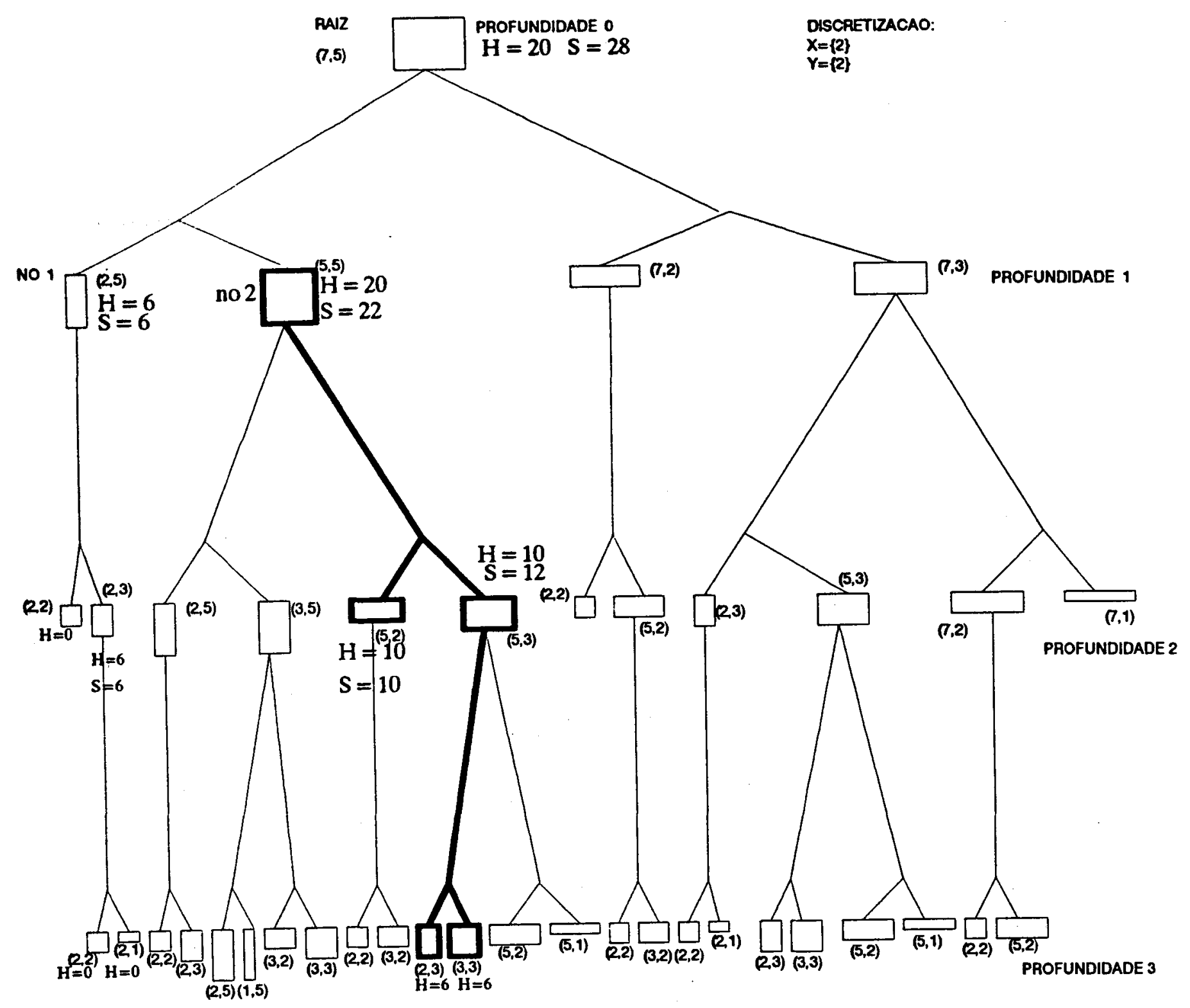

Figura 6.1: Exemplo do grafo-E/OU para o caso não-guilhotinado de ordem 0 


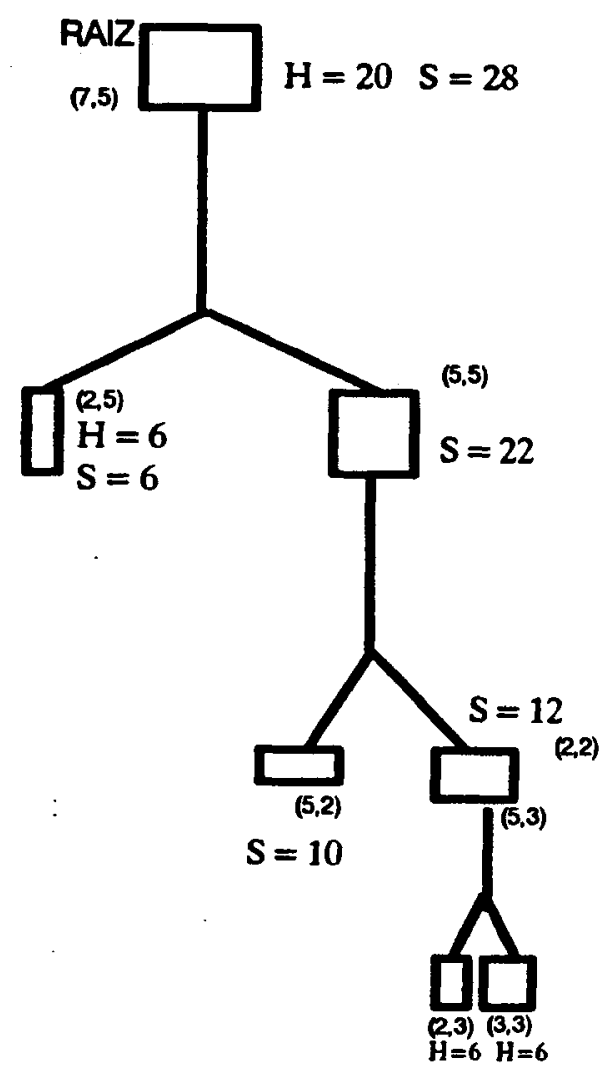

Figura 6.2: Melhor solução para a busca no grafo-E/OU da figura 6.1.

no grafo alguns dos retângulos inferiores poderiam ser cortados novamente, no entanto preferimos realizar uma busca até a "profundidade 3 " determinando o melhor valor até então, e realizar novos cortes apenas nos retângulos abertos que pertencerem à melhor solução encontrada.

A principio, o conjunto de discretização $X$, onde devem ser realizados os cortes verticais, deveria ser $X=\{2,4,5\}$. Pela propriedade de simetria nos cortes guilhotinados, $X$ foi reduzido a $X=\{2\}$. Como critério de comparação entre os retângulos produzidos até a profundidade 3 utilizaremos o melhor padrão homogêneo, ou seja, aquele que a somatória dos valores das peças cortadas seja o maior. O melhor homogêneo para cada retângulo está representado por $\mathrm{H}$ na figura 6.1 e a melhor solução por $\mathrm{S}$. $\mathrm{O}$ nó 2 , por exemplo, tem solução homogênea $H=20$ e melhor solução $S=22$, que é a determinada pelo caminho destacado em negrito.

A melhor solução produzida pela busca no grafo-E/OU da figura 6.1 é repre- 


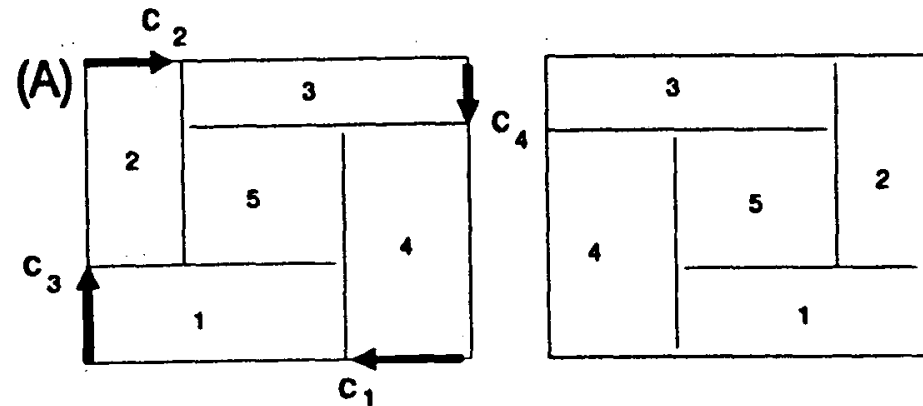

(B)
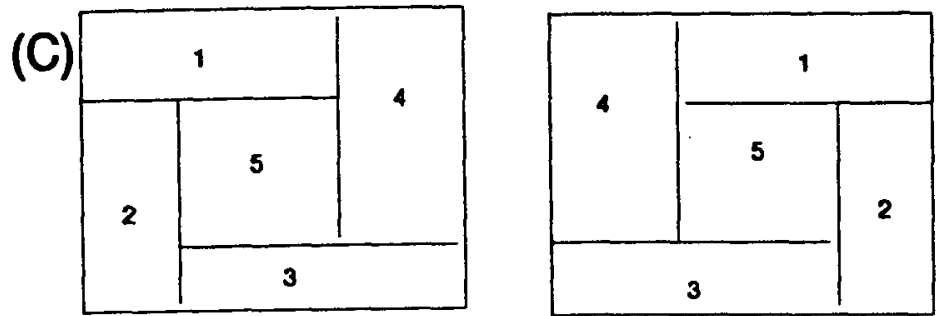

(D)

Figura 6.3: Simetria em cortes não-guilhotinados de ordem 1

sentada na figura 6.2 e tem valor 28 .

\subsection{Cortes não-guilhotinados de ordem 1}

Antes de introduzirmos ao grafo-E/OU os cortes não-guilhotinados de ordem 1, estudaremos algumas propriedades destes no grafo a fim de retirar do grafo-E/OU nós desnecessários.

\section{Simetria}

A figura 6.3 mostra quatro padrões (A), (B), (C) e (D) de cortes nâo-guilhotinados de ordem 1 , diferentes num mesmo retângulo. $O$ conjunto $\{[1],[2],[3]$, [4], [5] \} dos retângulos produzidos é o mesmo para todos eles. Vamos estabelecer regras tais que apenas um desses cortes seja considerado. no grafo-E/OU.

Observamos que os casos de cortes não-guilhotinados equivalentes (B) e (C) têm medidas $\left(\overrightarrow{c_{1}^{B}}, \overrightarrow{c_{2}^{B}}, \overrightarrow{c_{3}^{B}}, \overrightarrow{c_{4}^{B}}\right)$ e $\left(\overrightarrow{c_{1}^{C}}, \overrightarrow{c_{2}^{C}}, \overrightarrow{c_{3}^{C}}, \overrightarrow{c_{4}^{C}}\right)$ com direções opostas aos mesmos vetores $\left(\vec{c}_{1}^{A}, \vec{c}_{2}^{A}, \vec{c}_{3}^{A}, \vec{c}_{4}^{A}\right)$ e $\left(\vec{c}_{1}^{D}, \vec{c}_{2}^{D}, \vec{c}_{3}^{D}, \vec{c}_{4}^{D}\right)$ de $(\mathrm{A})$ e $(\mathrm{D})$, respectivamente. Assim, vamos nos restringir aos padrôes $(A)$ e $(D)$, ou seja, vamos considerar: 
- $\vec{c}_{1}$ com orientaşào da direita à esquerda: $\leftarrow$;

- $\vec{c}_{2}$ com orientaçào da esquerda à direita: $\rightarrow$;

- $\vec{c}_{3}$ com orientação de baixo à cima: $\uparrow \mathrm{e}$

- $\vec{c}_{4}$ com orientação de cima à baixo: $\downarrow$.

Com orientasão pré-fixada, podemos denotar a 4-upla $\left(\vec{c}_{1}, \vec{c}_{2}, \vec{c}_{3}, \vec{c}_{4}\right)$ por $\left(c_{1}\right.$, $\left.c_{2}, c_{3}, c_{4}\right)$ que representam as medidas dos respectivos vetores.

Consideremos $\left(c_{1}^{A}, c_{2}^{A}, c_{3}^{A}, c_{4}^{A}\right)$, a 4-upla que representa o padrão (A), $\mathrm{e}\left(c_{1}^{D}, c_{2}^{D}\right.$, $\left.c_{3}^{D}, c_{4}^{D}\right)$ a de (D). Então podemos afirmar que:

$$
\begin{aligned}
& c_{1}^{D}=c_{2}^{A} \\
& c_{2}^{D}=c_{1}^{A} \\
& c_{3}^{D}=c_{4}^{A} \\
& c_{4}^{D}=c_{3}^{A}
\end{aligned}
$$

Seguem as seguintes propriedades:

$$
\begin{aligned}
& c_{1}^{A}>c_{2}^{A} \text { se e somente se } c_{1}^{D}<c_{2}^{D} \\
& c_{3}^{A}>c_{4}^{A} \text { se e somente se } c_{3}^{D}<c_{4}^{D} \\
& c_{3}^{A}=c_{4}^{A} \text { se e somente se } c_{3}^{D}=c_{4}^{D}
\end{aligned}
$$

Além do que, podemos afirmar que um padrão de corte (A) deve satistazer as propriedades abaixo, sem as quais haveria uma degeneração do corte deixando de ser de ordem 1.

$$
\begin{aligned}
& c_{1}^{A}+c_{2}^{A}<L \\
& c_{3}^{A}+c_{4}^{A}<W
\end{aligned}
$$

Assim vamos considerar apenas os cortes onde $c_{1}^{A}+c_{2}^{A}<L$. Ainda assim podemos ter duplicação quando para (A) ou (D) $c_{1}=c_{2}$ :

$$
\begin{gathered}
c_{1}=c_{2} \text { e } c_{3}>c_{4} \text { produzindo o padrão (A) } \\
c_{1}=c_{2} \text { e } c_{3}<c_{4} \text { produzindo o padrão (D) } \\
c_{1}=c_{2} \text { e } c_{3}=c_{4}
\end{gathered}
$$

A fim de evitar tàis duplicações tomaremos apenas cortes $\left(c_{1}, c_{2}, c_{3}, c_{4}\right)$ que satisfaçam simultaneamente as seguintes condições:

$$
\begin{array}{lll}
\text { (I) } c_{1}+c_{2}<L & \text { (II) } c_{1}<c_{2} & \text { (III) Se } c_{1}=c_{2} \text { entâo } c_{3} \leq c_{4}
\end{array}
$$

Não estaremos perdendo nenhuma solução não-guilhotinada de ordem 1 já que se o corte produz (D), estamos com um corte equivalente a (A), (B) e (C). 
(A)

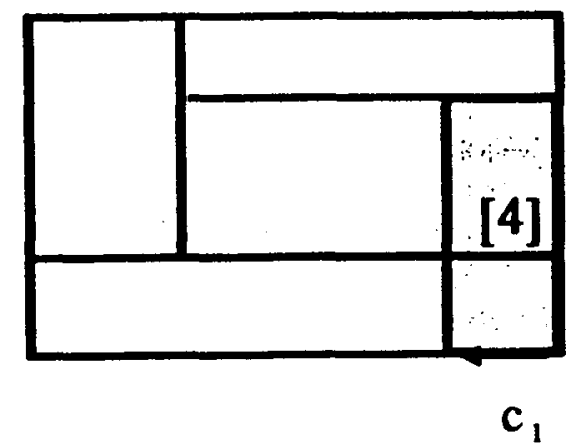

(B)

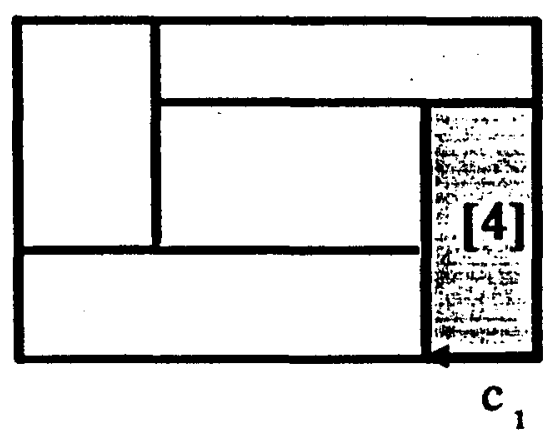

Figura 6.4: Padrâo não-guilhotinado de ordens 0 (A) e 1 (B) equivalentes

(A)

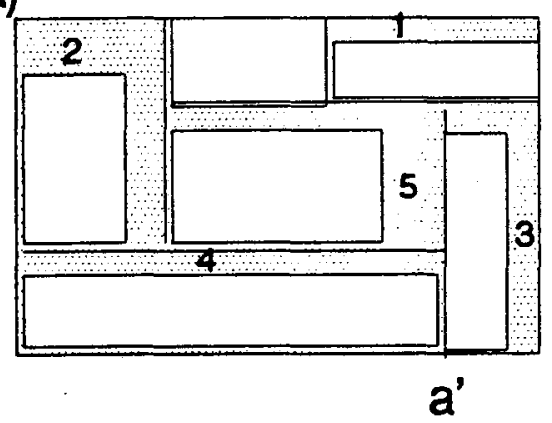

(B)

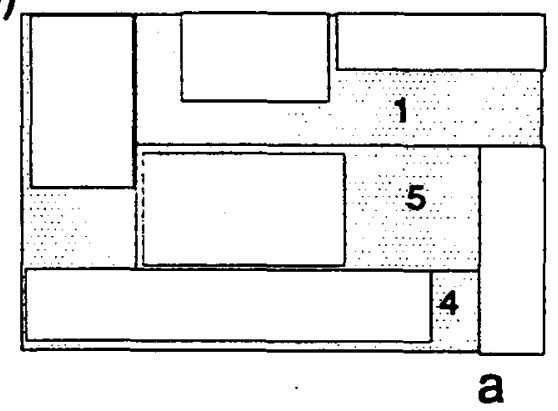

Figura 6.5: Processo de normalização para um padrão não-guilhotinado de ordem 1

\section{Normalização}

A normalização no padrão não-guilhotinado de ordem 1 tem o mesmo propósito dos padrôes guilhotinados, ou seja, de evitar que sejam executados cortes em pontos que ocasionam perdas desnecessárias na peça em estoque.

Se o corte $c_{2}$ for menor que $l_{\min }=\min \left\{l_{i}, \mathrm{i}=1,2, \ldots, \mathrm{m}\right\}$ por exemplo, nënhuma peça de encomenda poderá ser cortada no retângulo [4] de (A), veja a figura 6.4.(B). Será tido como perda a área do retângulo [4] e um padrão equivalente é produzido no grafo-E/OU nos arcos-E onde são permitidos apenas padróes de ordem 0. Assim tomaremos:

$$
c_{1}, c_{2} \geq l_{\min }, \text { e } c_{3}, c_{4} \geq w_{\min }
$$

Observe a figura 6.5. O padrão $(A)$ tem suas peças de encomenda o mais inferior e à esquerda possível. No entanto, as sobras que sâo desperdiçadas podem ser 
aproveitadas se ao invés de fazermos os corte $c_{1}$ em a', fizermos em a. As sobras do retângulo [3] passariam a fazer parte de [4] e [5], mas se somadas as sobras de [4] e [5] poderiam ser cortadas mais algumas peças de encomenda no padrào, veja (B). Aplicando este mesmo processo a $c_{2}, c_{3}$ e $c_{4}$ obtemos o padrão mostrado em (A).

Usando os cortes $c_{1}$ e $c_{2}$ em X e $c_{3}$ e $c_{4}$ em Y (veja seção 3.1), ou seja, usando os conjuntos de discretização $\mathrm{X}$ e $\mathrm{Y}$ evitamos construção de padrōes não normalizados.

No exemplo da figura 6.1 , onde $A_{0}=(7,5), A_{1}=(5,2)$ e $A_{2}=(2,3)$ com $v_{1}$ $=10$ e $v_{2}=6$ podemos estender o grafo- $\mathrm{E} / \mathrm{OU}$ com os arcos- $\mathrm{E}$ dos padrões não-guilhotinados de ordens 0 e 1 misturados. A figura 6.6 mostra os arcos- $E$ que complementariam o grafo-E/OU da figura 6.1.

A melhor solução para o problema em questão, é o representado na figura 6.7 e tem valor 32 superando o resultado anterior.

Este resultado não representa ser maior por acaso. Quando investigarmos junto ao grafo-E/OU de padrões não-guilhotinados de ordem 0 os padrões de ordem 1 , estaremos estendendo o grafo esperando obter resultados maiores ou iguais.

\subsection{Estratégia de busca}

Para gerar as possíveis soluções de corte no retângulo $A_{0}$, vamos estabelecer algumas regras para realizar a busca no grafo.

\section{O corte}

Un corte realizado em um retângulo A qualquer será representado pela 4upla $\left(c_{1}, c_{2}, c_{3}, c_{4}\right)$, satisfazendo as condições dadas por 6.1 e percorrendo os valores dos conjuntos de discretização.

Se o corte, por exemplo, é um corte horizontal, teremos $c_{1}=c_{2}=c_{4}$ e $c_{3} \neq 0$. Na formação dos cortes são prioritários os cortes guilhotinados, seguidos de não-guilhotinados de ordem 1. 


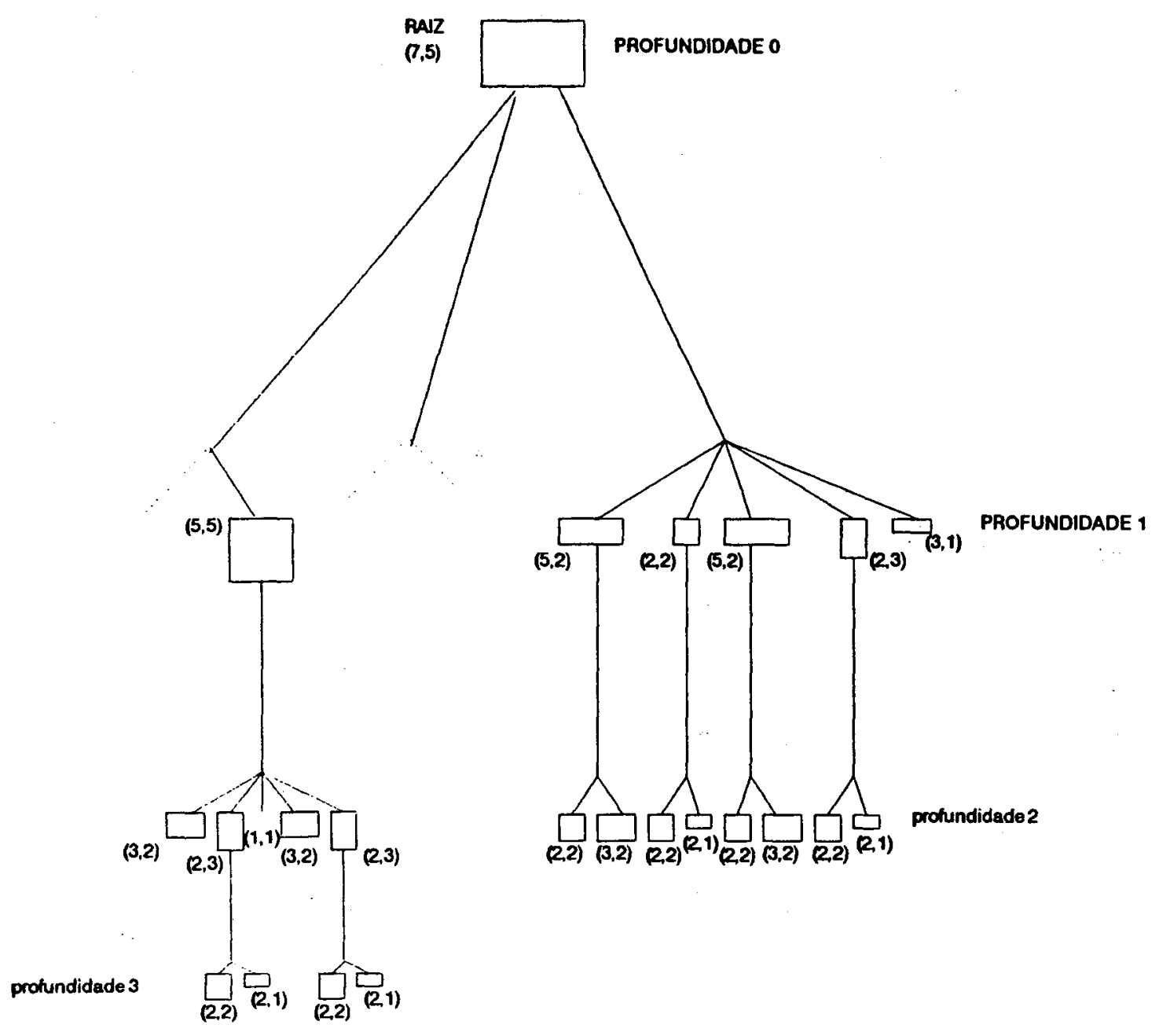

Figura 6.6: Arcos-E dos padrôes não-guilhotinados de ordem 1 aplicados ao grafo-E/OU da figura 6.1. 


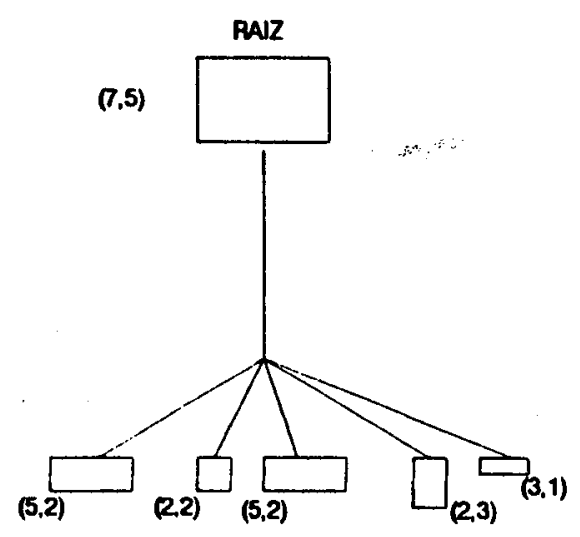

Figura 6.7: Melhor solução para o exemplo tomado.

\section{Busca em profundidade e em largura}

A busca em largura primeiro consiste em expandir os nós na ordem em que eles são gerados e a busca em profundidade primeiro expande os nós mais recentemente gerados, ou seja, a prioridade pode ser dada aos nós menos profundos ou aos mais profundos, respectivamente (veja Morabito[1992], pp. 79-81). A grande vantagem da busca em profundidade é a economia de memória.

\section{Backtracking}

Backtracking é uma variação da busca em profundidade primeiro que, ao invés de expandir, explora os nós mais recentemente gerados. $O$ último nó gerado passa a ser imediatamente escolhido se não for um nó onde não é possível mais nenhuma expansão. Um limite de profundidade deve ser estabelecido a priori, a partir do qual, o caminho é abandonado.

\section{Melhor solução homogênea}

A melhor solução homogênea $H(A)$ de um retângulo qualquer $A=(L, W)$, é um limitante inferior para a solução ótima de $\mathrm{A}$. H(A) é dado por:

$$
H(A)=\max _{1 \leq i \leq m}\left\{\left\lfloor l_{i} / L\right\rfloor\left\lfloor w_{i} / W\right\rfloor v_{i}\right\} .
$$


A seguir, é apresentado um algoritmo para efetuar a busca em profundidade utilizando a estratégia backtracking. Adotaremos 3 como o limite de profundidade.

PASSO 1. Seja uma lista chamada LIS composta pelo nó raiz, a melhor solução SOL como o melhor homogêneo $\mathrm{H}(\mathrm{SOL})$ para o retângulo $A_{0}$. E faça a profundidade PROF

\section{PASSO 2. PROF $\longleftarrow$ PROF +1}

Enquanto todos os cortes de LIS não estiverem investigados repita:

- Execute corte em LIS;

- Crie uma lista CORTE com os retângulos produzidos no corte;

- Faça a solução da lista SolLista:=0;

- Se PROF = 3

ENTÃO: Repita enquanto a lista CORTE $\neq$ vazia:

SolLista $\longleftarrow$ SolLista + H(CORTE)

CORTE $\longleftarrow$ proximo elemento da lista CORTE

SENÃO: Execute PASSO 2 com CORTE.

SolLista $\longleftarrow$ SolLista + H(CORTE)

CORTE $\longleftarrow$ próximo elemento da lista CORTE

Se SolLista > SOL ligar corte à LIS.

Se existir alguma lista anterior ligado a LIS com a mesma profundidade de CORTE, descarte-a.

$$
\text { Faça SOL } \longleftarrow \text { SolLis }
$$

Na próxima parte apresentaremos a finalização do estudo, relatando os resultados computacionais, conclusão e perspectivas. 


\section{Parte IV}

\section{Considerações finais}




\section{Capítulo 7}

\section{Conclusão}

Neste capítulo são apresentados os resultados obtidos com comentários e, em seguida, algumas idéias para estudos posteriores sâo sugeridas.

Após levantamento dos diferentes métodos encontrados na literatura para solucionar o problema de corte bidimensional não-guilhotinado, este estudo propôs uma nova forma de resolver o problema. Para verificar a viabilidade da proposta foi realizada uma implementaçâo em TURBO PASCAL para o método e executado num microcomputador compativel com IBM-286.

Como o problema que consideramos podem ser utilizados para o carregamento de paletes, tomamos exemplos onde as peças de encomendas são um conjunto de caixas retangulares de mesma altura e que devem ser alocadas em um palete, também retangular. Assim rotaçôes são permitidas, se consideramos a peça $\left(l, w^{\prime}\right)$ como peça de encomenda também consideramos $(\mathrm{w}, \mathrm{l})$ como tal.

A seguir apresentamos alguns exemplos cujas soluções foram obtidas pelo programa. Cada tabela mostra as dimensões da placa e das peças, e o valor $v_{i}$ de cada peça foi tomada como a área, ou seja, $v_{i}=l_{i} w_{i}$. Assim, a soluçâo ótima dividida por $L_{0} W_{0}$, fornece a área utilizada. 


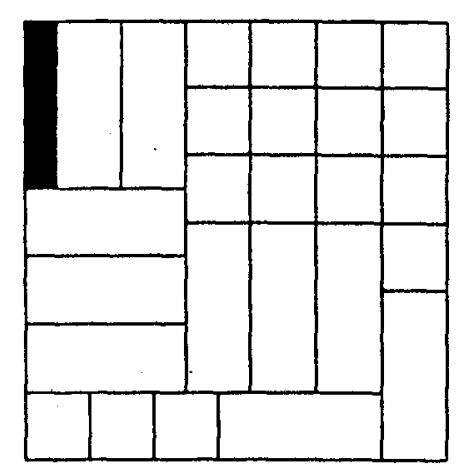

Figura 7.1: Padrão obtido para o exemplo 1.

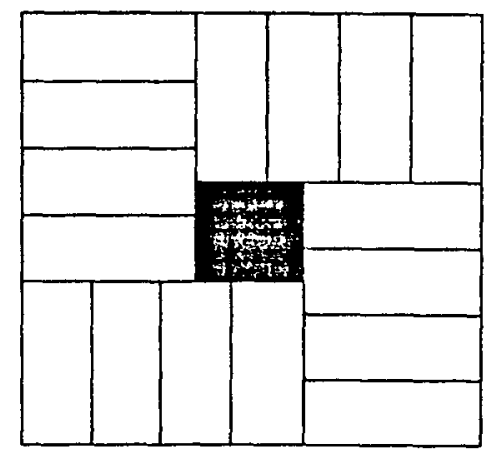

Figura 7.2: Padrão obtido para o exemplo 2.

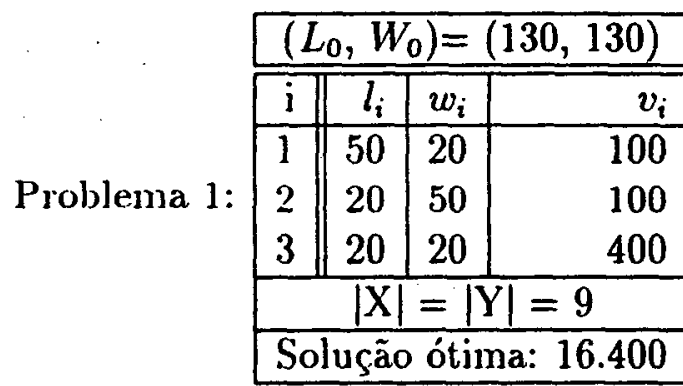

Problema 2: \begin{tabular}{|r||c|c|r|}
\hline \multicolumn{4}{|c|}{$\left(L_{0}, W_{0}\right)=(130,130)$} \\
\hline \hline $\mathrm{i}$ & $l_{i}$ & $w_{i}$ & $v_{i}$ \\
\cline { 2 - 4 } & 50 & 20 & 100 \\
2 & 20 & 50 & 100 \\
\hline \multicolumn{3}{|c|}{$|\mathrm{X}|=|\mathrm{Y}|=9$} \\
\hline \multicolumn{3}{|c|}{ Soluçâoo ótima: 16.900} \\
\hline
\end{tabular}

Nos exemplos observamos que tomamos no primeiro caso 3 peças de encomenda, duas das quais sào mais alongadas, $A_{1}$ e $A_{2}$. $O$ resultado que temos é um corte guilhotinado. Para o segundo problema não consideramos a peça quadrangular, $A_{3}$, obtendo um 
padrão de corte não-guilhotinado. A expectativa é de que, quando tomarmos peças mais alongadas, vamos obter padrões de corte com cortes não-guilhotinados de ordem 1.

Não foi possível a obtençâo de problemas maiores com esta implementação. Para melhor desempenho do programa seria necessário uma reestruturação de dados e a implementação de heurísticas mais adequadas. A aplicação de heurísticas é uma prática indispensável no tratamento de grafos muitos extensos, como é o nosso caso.

Uma forma de heuristica que poderíamos tomar é permitir que cortes não-guilhotinados de ordem 1 sejam praticados somente até uma certa profundidade no grafo e a partir de então usar apenas cortes guilhotinados. Observe ainda que estas heurísticas podem ser eficientes somente para determinados tipos de problemas, variando de acordo com seu valor associado, comprimento, ou largura.

Este método sugere bons resultados para problemas de cortes bidimensionais regulares. Pois o resultado final, no mínimo, será o mesmo obtido por cortes restritos a guilhotina. Podendo, por exemplo, ser estudado para problemas de carregamento de paletes com peças a serem carregadas de mesma altura.

A contribuição científica dada por este trabalho foi proporcionar um novo método para resolver o problema de corte bidimensional não-guilhotinado. A abordagem em grafo-E/OU tem sido pesquisada para problemas guilhotinados com muito sucesso, podendo assim oferecer boas perpectivas para o não-guilhotinado. 


\section{Apêndice A}

\section{Relaxação lagrangeana e método do subgradiente}

A relaxação lagrangeana consiste em relaxar restrições que representam uma dificuldade para resolução do problema, introduzindo-se uma penalidade na função objetivo pela não verificação das restrições relaxadas.

Seja o problema de programação linear inteira:

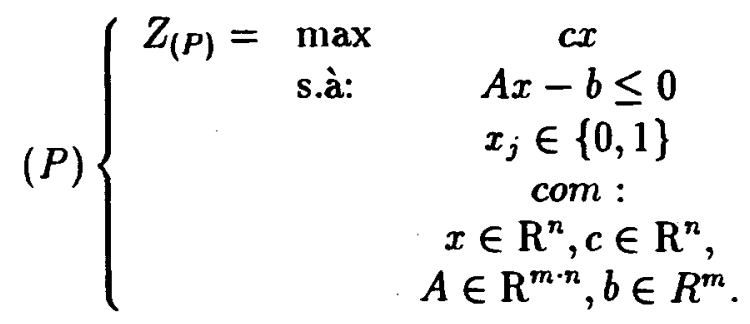

Denotaremos por $\mathrm{F}(\mathrm{P})$ o conjunto das soluções factíveis do problema $(P)$.

Introduzindo $\lambda \geq 0 \in \mathrm{R}^{m}$, que chamamos multiplicadores de Lagrange, a relaxação lagrangeana de $(P)$ em relação a restriçâo $A x-b \leq 0$ é definida por:

$$
\left(R P_{\lambda}\right)\left\{\begin{array}{ccc}
Z_{\left(R P_{\lambda}\right)}= & \max & L(x, \lambda) \\
& \text { s.à: } & x_{j} \in\{0,1\}
\end{array}\right.
$$

onde $L(x, \lambda)=c x+\lambda(b-A x)$ é denominada função lagrangeana e $Z_{\left(R P_{\lambda}\right)}$ é chamada função dual.

Dizemos que a restrição $A x-b \leq 0$ do problema $(P)$ foi dualizada e o problema resultante é o problema lagrangeano. 
Podemos observar que, para todo $x \in F(P)$ temos $A x-b \leq 0$ e, desde que, $\lambda \geq 0$ então:

$$
L(x, \lambda) \geq c x, \forall x \in F(P) e \lambda \geq 0
$$

A importância de qualquer relaxação de $(P)$ é determinada pela proximidade do valor objetivo desta e o valor objetivo de $(P)$. Assim se fazemos a escolha para os valores dos multiplicadores $\lambda$ resolvendo o seguinte problema:

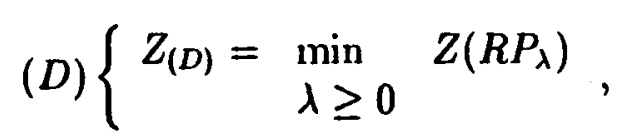

que é chamado problema dual lagrangeano, obtemos a solução mais apropriada para $\lambda$.

O método do subgradiente foi desenvolvido com a finalidade de encontrar a solução para o problema lagrangeano dual, método este que descrevemos a seguir.

Existem várias extensões do método do subgradiente, que consistem basicamente no deslocamento, a cada iteração $k$, na direção de um subgradiente da função considerada, ou seja:

$$
\lambda^{k+1}=\lambda^{k}-t_{k} \frac{g^{t}\left(\lambda^{k}\right)}{\left\|g\left(\lambda^{k}\right)\right\|}
$$

onde $g\left(\lambda^{k}\right)$ é um subgradiente da função considerada. Se $x^{0}$ é uma solução ótima de $R P_{\lambda_{k}}$ então $\left(b-A x^{0}\right)$ é um subgradiente da função dual em $\lambda$.

Polyak[1969] ${ }^{1}$, citado por Florentino[1990], mostrou que a sequência de valores $Z\left(R P_{\lambda_{k}}\right)$ tem convergência linear quando $t_{k}$ for definido da seguinte forma:

$$
t_{k}=\sigma_{k} \frac{Z(D)-Z\left(R P_{\lambda^{k}}\right)}{\left\|g\left(\lambda^{k}\right)\right\|^{2}}
$$

onde $0<\sigma_{k} \leq 2, \forall k$.

Na prática o desconhecimento de $Z(D)$ leva a trabalhar com estimativas $\bar{Z}$ de $Z(D)$, portanto é usual o passo ser escolhido pela fórmula:

\footnotetext{
'POLYAK, B. T. - "Minimization of unsmooth functionals", URSS Computational Mathematics and Mathematical Pliysics, vol. 9, pp. 14-29
} 


$$
t_{k}=\sigma_{k} \frac{\bar{Z}-Z\left(P L_{\lambda^{k}}\right)}{\left\|g\left(\lambda^{k}\right)\right\|^{2}}
$$

onde $0<\sigma_{k} \leq 2, \forall k$.

Para determinar $\sigma_{k}$, Beasley[1985a] utilizou a estratégia de Held et al. ${ }^{2}$, citada por Florentino[1990], que consistem em:

Passo 1: Entre com valores iniciais para:

$$
\begin{gathered}
\eta_{0} \text { (número de iterações), } \\
\rho \text { (valor mínimo para } \sigma_{k} \text { ), } e \\
r \text { (número mínimo de iterações.) }
\end{gathered}
$$

Passo 2: Faça:

$$
\begin{aligned}
& \sigma \leftarrow 2 \\
& \eta \leftarrow \eta_{0}
\end{aligned}
$$

Passo 3: Enquanto $\sigma>\rho$ faça:

$$
\begin{array}{ll}
\sigma \leftarrow \frac{o_{k}}{2} & \\
\text { Se } \eta>r & \text { então } \eta \leftarrow \frac{\eta}{2} \\
& \text { senão } \eta \leftarrow r
\end{array}
$$

Beasley[1985a] inicializou este procedimento com $\eta_{0}=(|L|+|W|), \rho=0.005 e$ $r=5$ para o problema tratado no capítulo 4 .

\footnotetext{
${ }^{2}$ HELD, M., WOLFE, P. \& CROWDER, H. D.(1974) - "Validation of Subgradient Optimization", Mathematical Programming 6, pp. 62-88.
} 


\section{Bibliografia}

[1] -ÁRCARO , V. F.(1988) Recorte de estoque unidimensional. São Carlos. (Mestrado - Instituto de Ciências Matemáticas de São Carlos/USP).

[2] -BEASLEY, J. E. (1985a) - An exact two-dimensional non-guillotine cutting tree search procedure - Journal of Operations Research Society, vol. 33, no 1: pp. 49-64.

[3] -BEASLEY, J. E. (1985b) - Bounds for two-dimensional cutting - Journal of Operations Research Society, vol. 36, no 1: pp.71-74.

[4] -BIRÓ, Milós \& BOROS, Endre (1984) - Network flows and non-guillotine cutting patterns - European Journal of Operational Research, vol. 16: pp. 215-221.

[5] -BISCHOFF, E. \& DOWSLAND W. B. (1982)- An application of the micro to product design and distribuition - Journal of Operational Research Society, vol. 33, nọ 3: pp.271-280.

[6] -CHRISTOFIDES, N. \& WHITLOCK, C. (1977)- An algorithm for twodimensional cutting problems - Journal of Operations Research Society, vol. 25, no 1: pp. 30-44.

[7] -DOWSLAND, Kathryn A. (1987)- An exact algorithm for the pallet loading problem - European Journal of Operational Research, vol. 31: pp. 78-84.

[8] -DOWSLAND, Kathryn A. (1990) - Efficieent automated pallet loading - European Journal of Operational Research, vol. 44: pp.232-238.

[9] -FARLEY, Alan A. (1988)- Mathematical programming models for cutting-stock problems in the clothing industry - Journal of Operational Research Society, vol. 39, nọ 1: pp.41-53.

[10] -FARLEY, Alan A. (1990) The cutting stock problem in the canvas industry Journal of Operational Research Society, 44: pp. 247-255. 
[11] -FLORENTINO, Helenice de O. (1990)- Relaxação lagrangeana em programação inteira. São Carlos. (Mestrado - Instituto de Ciências Matemáticas de São Carlos/USP).

[12] -GILMORE, P. C. \& GOMORY, R. E. (1961)- A linear programming approach to the cutting-stock problem - Operations Research, vol.9: pp. 849-859.

[13] -GILMORE, P. C. \& GOMORY, R. E. (1963)- A linear programming approach to the cutting stock problem - part II - Operations Research, vol. 11, pp. 863-888.

[14] -GILMORE, P. C. \& GOMORY, R. E. (1965)- Multistage cutting stock problems of two and more dimensions - Journal of Operational Research Society, vol.13: pp. 94-120.

[15] -HILLIER, Frederick S. \& LIEBERMAN, Gerald J. (1988)- Introduçâo à pesquisa operacional - São Paulo - Editora Campus.

[16] -MORABITO, R. N. (1989)- Corte de estoque bidimensional. São Carlos. (Mestrado - Instituto de Ciências Matemáticas de São Carlos/USP.

[17] -MORABITO, R. N. \& WIDMER, J. A. (1991)- O problema do carregamento de paletes - uma metodologia para o carregamento com embalagens de dimensôes iguais. In: CONGRESSO NACIONAL DA ANPET (Associação Nacional de Pesquisa e Ensino em Transporte) DE ENGENHARIA DE TRANSPORTES, V, São Carlos, 1991.

[18] -MORABITO, R. N.; ARENALES M. N. \& ÁRCARO V. F. (1991)- An-orgraph approach for two-dimensional cutting problems - European Journal of Operational Research, vol. 58: pp.1-9.

[19] -MORABITO, Reinaldo N. (1992)- Uma abordagem em grafo-e/ou para o problema do empacotamento: aplicação ao carregamento de paletes e contêineres. (Doutorado - Escola de Engenharia de São Carlos/USP).

[20] -OLIVEIRA, José F. \& FERREIRA, José S. (1990)- An improved version of Wang's algorithm for two-dimensional cutting problems - European Journal of Operational Society vol. 44: pp.256-266.

[21] -SCHIRIJVER, Alexander (1986)- Theory of linear an integer programming John-Wiley \& Sons Ltd..

[22] -SILVA, Alexandre J. M.; CINTRA, Glauber F. (1991)- Geração de modelos de corte a duas e três dimensôes - XI Congresso Nacional da Sociedade Brasileira de Computação, pp. 362-372. 